\title{
EL CASTRO DE "LA MESILLA” (ALANGE, BADAJOZ): APUNTES PARA LA DEFINICIÓN DE LA SEGUNDA EDAD DEL HIERRO EN EL VALLE DEL MATACHEL
}

\author{
IGNACIO PAVÓN SOLDEVILLA ${ }^{1}$ \\ Área de Prehistoria. Universidad de Extremadura
}

A Flora, cuyo recuerdo nos llega desde donde sopla el Céfiro.

\section{Resumen}

El presente articulo trata de contribuir a la caracterización de la Segunda Edad del Hierro en el Valle del Matachel (Badajoz), uno de los espacios más atractivos, aunque peor conocidos, de la protohistoria extremeña. A partir del estudio de una amplia muestra de materiales cerámicos recogidos en el castro de "La Mesilla" (Alange) y de la contextualización espacial de este enclave, se ofrecen claves para entender los notables procesos de ruptura cultural que la realidad prerromana (celtici $y$ turduli) representó en el substrato bajoextremeño del Bronce FinalOrientalizante.

\section{Abstract}

This article tries to contribute to the definition of the Second Iron Age in Matachel's Valley (Badajoz), one of the most atractive and unknown areas in the recent Prehistory of Extremadura. Keys for understand the cultural rupture that the pre-Roman tribes (celtici and turduli peoples) caused in the society previous to the Late Bronze Age-Orientalizing Period in the South of Extremadura are shown leaving from the study of a large pottery collection picked out from the "castro" known as "La Mesilla" (Alange) and from its spatial analysis.

\footnotetext{
' Este trabajo no hubiese sido posible sin la colaboración de J.D. Carmona y D. Duque
} 
Desde mediados de los años ochenta, la investigación arqueológica extremeña viene centrando buena parte de sus esfuerzos en el estudio y la definición-desde diversos prismas y con resultados también a veces divergentes- de los procesos protohistóricos acaecidos durante la Segunda Edad del Hierro en las distintas tierras que conforman esa región (Rodríguez Diaz, 1987, 1989, 1990, 1994, 1995 a, b, c; Berrocal, 1992; Salinas y otros, 1993; Almagro y Martín, 1994; Velázquez y Enríuez, 1995; Ortiz y RodrígueZ, 1998; entre otros). Lejos se está ya, pues, de identificar la época prerromana, como incipientemente plantearan Mario Roso de Luna (1901, 1904 a y b, 1908) y el Marqués de Monsalud (1901), con el difuso mundo de las "citanias"... y, sin embargo, continuamos encontrando no pocos problemas a la hora de descender a la caracterización concreta de determinados espacios.

Este es, sin duda, el caso del Valle del Matachel (Badajoz), un espacio abierto y bien definido a nivel geográfico, un eje que, separando la Tierra de Barros de la comarca de La Serena -y las Vegas Bajas de las Altas, en su afluencia al Guadiana-, se vislumbra como uno de los principales puentes de conexión entre la submeseta sur, a través de Extremadura, y Andalucía. En Azuaga (Badajoz), divisoria de cuencas, nace el Matachel, pero también el Bembézar, que desemboca en el Guadalquivir poco antes de Palma del Río (Córdoba). De la misma manera que desde este punto de vista cabe destacar su carácter confluyente, también en el Valle del Matachel se ha venido situando por las fuentes clásicas, aunque de una forma un tanto imprecisa, el límite o confluencia entre los dos pueblos, "célticos" y "túrdulos o turdetanos”, que -según los geógrafos y etnógrafos de la Antigüedad Plinio (Naturalis Historia, III, 13-15) y Strabón (Geografía, III, 1, 6)- poblaban el territorio de la Beturia poco antes de la conquista romana (GARCía Iglesias, 1971). Pero más allá de su naturaleza fronteriza, algunas referencias puntuales permiten, incluso, defender la pertenecia de este valle al ámbito de los túrdulos (Rodríguez Díaz, 1995a: 210; Berrocal, 1995: 159).

Avanzando en esta breve introducción, la Beturia Túrdula prerromana vendría definida básicamente por el poblamiento aglutinado en torno a la mitad oriental de la Cuenca Media del Guadiana, al Valle del Zújar y al propio Matachel, al margen del que se extiende al norte de Córdoba y parte de Ciudad Real (OrTiz y Rodríguez, 1998: 255). Desde un punto de vista estrictamente arqueológico, en el círculo etnocultural túrdulo-turdetano se ha venido defendiendo un cierto desequilibrio demográfico entre el centro -aparentemente vacío- y la periferia -algo más poblada-, explicable en función tanto de la atonía que globalmente presenta esta zona tras fases previas más dinámicas, como de la efervescencia apreciable en sus áreas limítrofes, especialmente en la Beturia Céltica (Rodríguez DíAz, 1994 y 1995a: 223). En este contexto de despoblamiento, no ha dejado de señalarse tampoco el conocimiento diferencial existente entre los ámbitos del Guadiana y el Zújar frente a la todavía escasamente estudiada cuenca del Matachel (Rodríguez Díaz, 1995a: 222), para la que apenas hemos venido contando hasta hoy con la información procedente exclusivamente de los materiales de superficie recogidos en los poblados de las Dehesillas de Higuera de Llerena (Rodríguez E IŃESTA, 1984), el Cerro del Castillo de Bienvenida, la Sierra de la Oliva, Azuaga o, ya cerca de su desembocadura en el Guadiana, en el propio Castillo de Alange (Rodríguez Díaz, 1987). A este panorama del Matachel, ciertamente deficitario de documentación, y cuyo único yacimiento excavado es el de Hornachuelos (Ribera del Fresno) -que cronológicamente parece 
restringirse exclusivamente a época romano-republicana (Rodríguzz DíAz, 1995a: 236; 1995c: 166 y 170)-, cabe sumar un hallazgo reciente, el poblado de La Mesilla, también en Alange, del que específicamente tratan las siguientes páginas (figura 1).

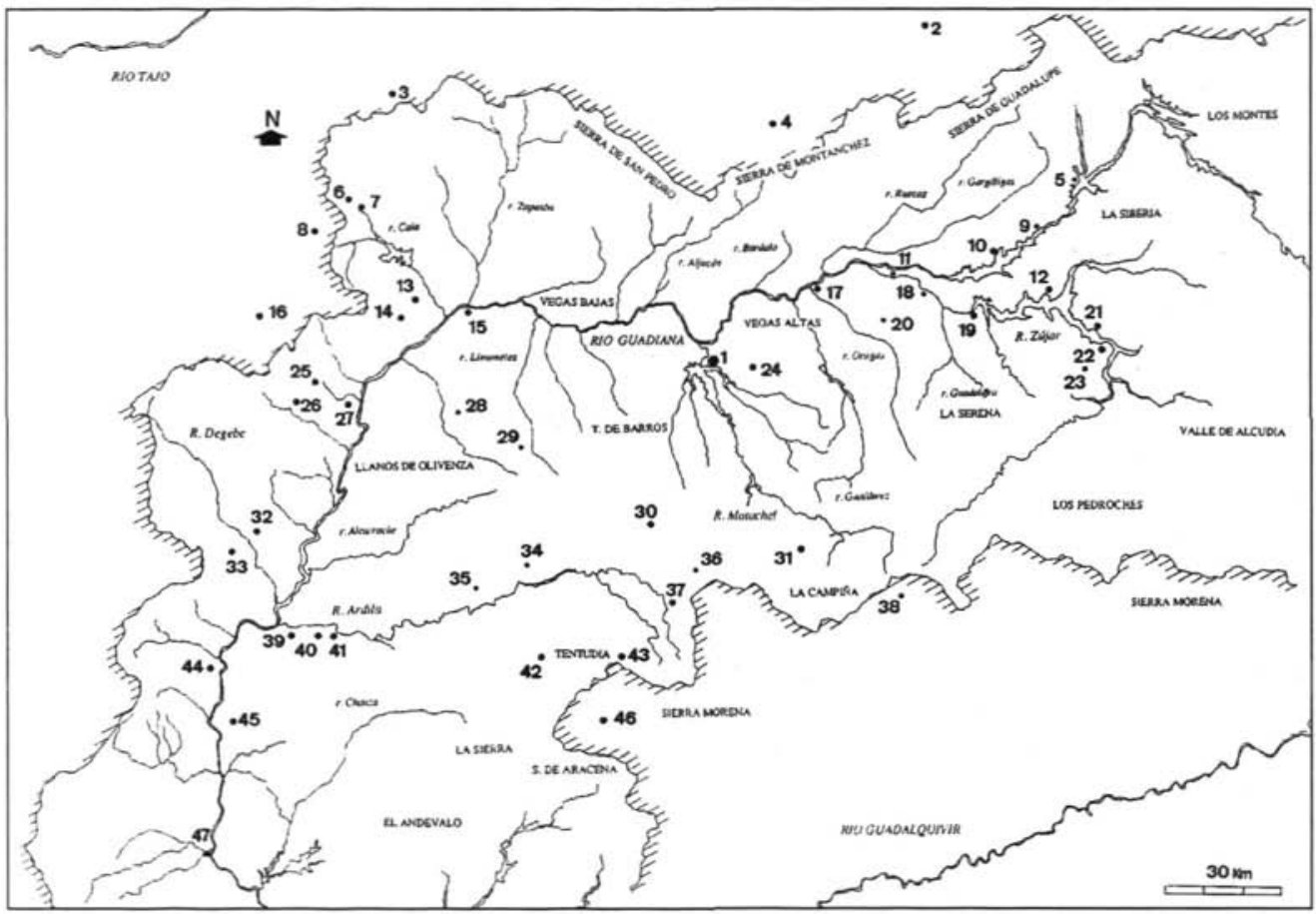

Figura 1: Principales yacimientos del Hierro II en la Cuenca Media del Guadiana: 1- La Mesilla, 2- La Coraja, 3- El Jardinero, 4-Botija, 5-Cerro de la Barca, 6-Safára , 7- Baldío, 8-Vaiamonte, 9- Los Castillejos de Puebla de Alcocer,

10- Cogolludo, 11- Entreríos, 12-Los Vadillos, 13- Segovia, 14-Elvas, 15- Alcazaba de Badajoz, 16- Castelo de Veiros. 17-Medellín, 18- El Casarón, 19- Embalse del Zújar, 20-Magacela, 21- Tabla de las Cañas, 22- Peñón del Pez, 23- Las Poyatas, 24- Sierra de la Oliva, 25- Rio de Moinhos, 26- Herdade das Casas, 27- S. Miguel da Mota, 28Cerro del Castillo de Valverde de Leganés, 29- Sierra de Monsalud, 30- Ermita de Belén, 31- Las Dehesillas, 32 Castelo Velho do Degebe, 33- Monte Murado, 34- Castillo de Jerez, 35- Los Castillejos de Oliva de la Frontera, 36 Cerro del Castillo de Bienvenida, 37- Los Castillejos-2 de Fuente de Cantos, 38- Castillo de Azuaga, 39- Azougada, 40- Castelo de Moura, 41- Castelo Velho de Safára, 42-Castrejón de Capote, 43- La Martela, 44- Cerro Furado, 45Castelo de Serpa, 46- El Castañuelo, 47-Mértola, 48- Alcoutim.

\section{DEFINICIÓN ESPACIAL DEL CASTRO DE LA MESILLA}

Desde principios de siglo se viene situando en las inmediaciones de Alange, y más concretamente en el Cerro del Castillo, un importante yacimiento vinculado por el Marqués de Monsalud al mundo prerromano de las "citanias" en unos términos que muy bien podrían 
parecernos los de un nuevo Schliemann evocando a la dorada "Micenas" de Homero². Con el correr del tiempo -y más concretamente en los últimos años-, al margen de constatarse una vez más la circunstancia apuntada por ese erudito, se ha procedido a valorar, desde una nueva visión la ocupación de dicho enclave. Con un origen en las primeras fases de la Edad del Bronce y un desarrollo estratigráfico bien constatado hasta el Bronce Final (PAvón, 1995), la aparición de elementos aislados en superficie adscribibles tanto al Orientalizante -especialmente una fíbula de doble resorte recuperada en superficie- como al Hierro II/época romano-republicana (RODRíguez Díaz, 1995a: 251) han permitido defender una ocupación prácticamente ininterrumpida a lo largo de toda la Protohistoria, en parte explicable por sus peculiares condiciones topográficas en el marco de la "Cuenca Media del Guadiana". Junto a dicha personalidad geográfica, que resulta restringida a unos cuantos puntos de lo que más restrictivamente se entiende como "Valle Medio del Guadiana", esa aparente continuidad ocupacional ha contribuido a apuntar, en un primer momento (PAvón, 1995: 872-879), y conceptualizar, poco después (Rodriguez DiAz, 1995c: 167-169; ENRíquez y otros, 1998: 160), el "poblado de vado" como una de las entidades más personalizadas de la denominada "Facies Guadiana". Así las cosas, se ha venido subrayando el papel del Cerro del Castillo de Alange como el del vertebrador posiblemente más importante en el poblamiento de esta comarca antes de la fundación de Mérida.

Sin embargo, la base documental que da pie al presente estudio no procede de ese gran yacimiento, sino de las inmediaciones del enclave conocido como "La Mesilla", ubicado en las cotas más altas, y al nordeste, del actual casco urbano de Alange (351 m. snm.). Distante escasamente unos $1000 \mathrm{~m}$. del Cerro del Castillo, se sitúa en lo que puede considerarse una prolongación del mismo hacia la Sierra de Peñas Blancas. Concretamente, el espacio que -en función de la topografía y la dispersión superficial de restos arqueológicos- parece configurar el núcleo de este asentamiento se define por una extensión mucho más modesta, de 180 x $90 \mathrm{~m}$. (aprox.), con planta de tendencia elíptica y eje mayor en sentido E-W. Todos los indicios apuntan la existencia de un pequeño "castro", desconocido para la investigación hasta el presente (Rodriguez Diaz, 1987; Enríuez y Jiménez, 1989; CALERO y MárQueZ, 1991; Enríquez, 1997). Notablemente alterado por construcciones relativamente recientes, hemos podido recuperar en los archivos de Paisajes Españoles una imagen bastante esclarecedora del aspecto que presentaba hasta no hace muchos años (figura 2). Para entender la fisonomía del nuevo yacimiento que ahora presentamos es preciso tener en cuenta que dicho

2 -El castillo de Alanje nos presenta otro análogo ejemplo. Asunto desde antiguo en la imaginación popular de toda clase de maravillosos relatos de tesoros ocultos, es preciso convenir que tenían algún fundamento, pues no hay sitio en nuestra región del que más abundantes hayan brotado los objetos de metal precioso pertenecientes a la época prehistórica. Desgraciadamente todo ha venido a desaparecer, ya fundiéndose, ya cayendo en poder de cualquier obscuro aficionado; pues, a la verdad, tan funesto próximamente resulta para la ciencia el crisol del platero como los seños arcanos de la gaveta de esos señores que la dan de coleccionistas. He oído hablar de argollas de oro macizo alli encontradas, indudablemente torques o brazaletes, y de no pocos hallazgos. Procedentes de allí poseo varias alhajas destinadas al adorno personal, todas de oro; unos pequeños conos de dos centímetros de altura que presentan en su base una hilera de agujeros destinados, al parecer, a coserlos sobre los vestidos, una bonita sortija de alambre arrollado en forma de espiral y un brazalete abierto de forma curva para adaptarse a la muñeca, conviniendo advertir que otro brazalete de idéntica forma, aunque de bronce, fue encontrado en las excavaciones de Sabroso." (Movsalld, 1901: 11-12). 


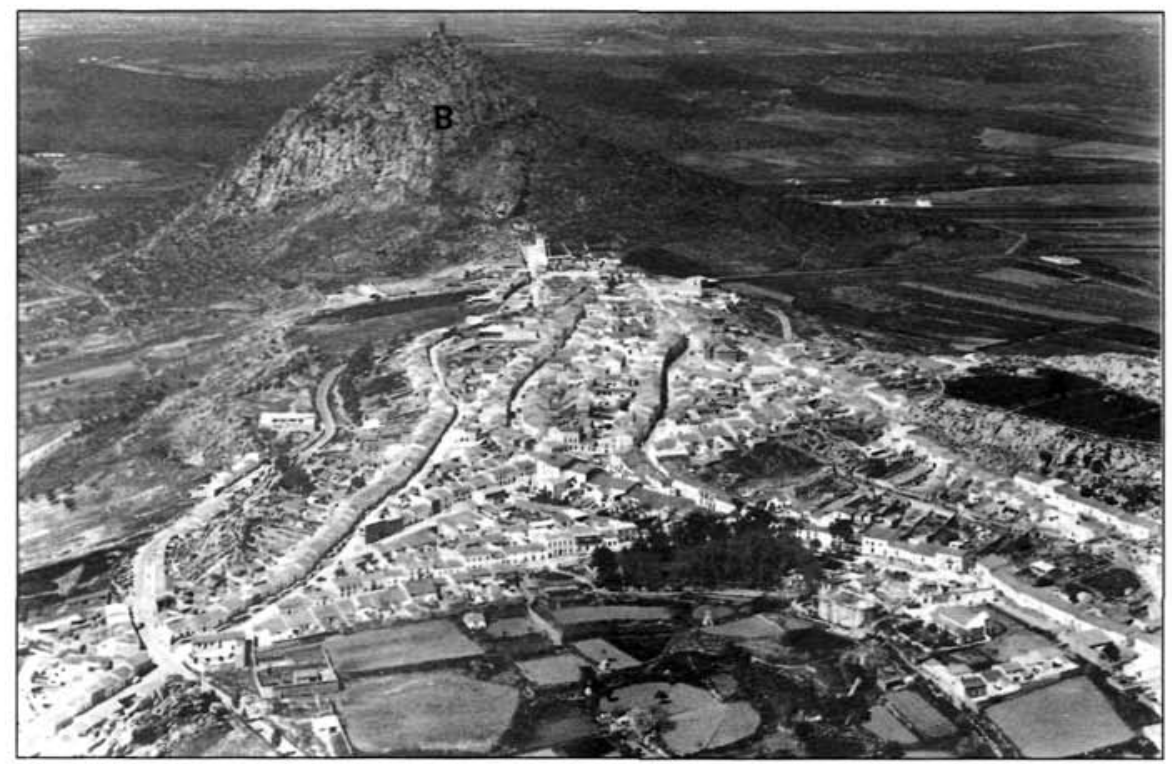

Figura 2. Vista panorámica con el castro de La Mesilla a la derecha

(a) y el Cerro del Castillo de Alange más atrás (b) (foto de "Paisajes Españoles").

espacio, especialmente concentrado en una especie de mesetilla, se encuentra perfectamente protegido de los vientos del norte por los "Canchos de La Mesilla", una cresta rocosa que, además, oculta la percepción del sitio desde el río Guadiana. Ello no implica, sin embargo, que el curso de este importante río no pueda vigilarse fácilmente accediendo a la mencionada elevación. Este interés por pasar desapercibido se potencia, además, por la propia elección del enclave, situado entre dos importantes elevaciones como son la Sierra de Peñas Blancas (662 m.) y el Cerro del Castillo de Alange ( $485 \mathrm{~m}$.), al este y oeste, respectivamente. Al sur, el castro está perfectamente defendido por la propia orografía de la ladera, entre las rocas, que súbitamente se precipita hasta el río Palomillas $(225 \mathrm{~m}$.), afluente del Matachel.

Los materiales arqueológicos que seguidamente publicamos fueron puestos en nuestro conocimiento por D. Juan Diego Carmona Barrero, aficionado a la arqueología, que los recuperó en el verano de 1997 tras efectuarse un movimiento de tierras en la propiedad de D. Félix Sánchez Carrillo, al este del Colegio Público Cervantes, en una zona donde ya la pendiente se suaviza y ofrece acomodo al hábitat. Dichas maniobras pusieron también al descubierto algunos tramos de muros rectos, pertenecientes a viviendas, cuyas plantas resulta imposible adivinar sin el desarrollo de una excavación sistemática. El interés de esta eventual intervención se acentúa si tenemos en cuenta que una buena parte del yacimiento parece encontrarse notablemente alterada por la construcción, realizada en los años ochenta, del mencionado colegio. En estas circunstancias, sólo las parcelas que permanecen sin construirse al este de dicho edificio -y en cuya superficie se adivina vagamente el trazado de algunos otros muros de piedra- podrán ser susceptibles de una excavación arqueológica que per- 
mita obtener una radiografía de la ocupación (figuras 3 y 4). Por el momento, sin embargo, su evaluación pasa por el estudio de los materiales, principalmente cerámicos, recogidos en este asentamiento.

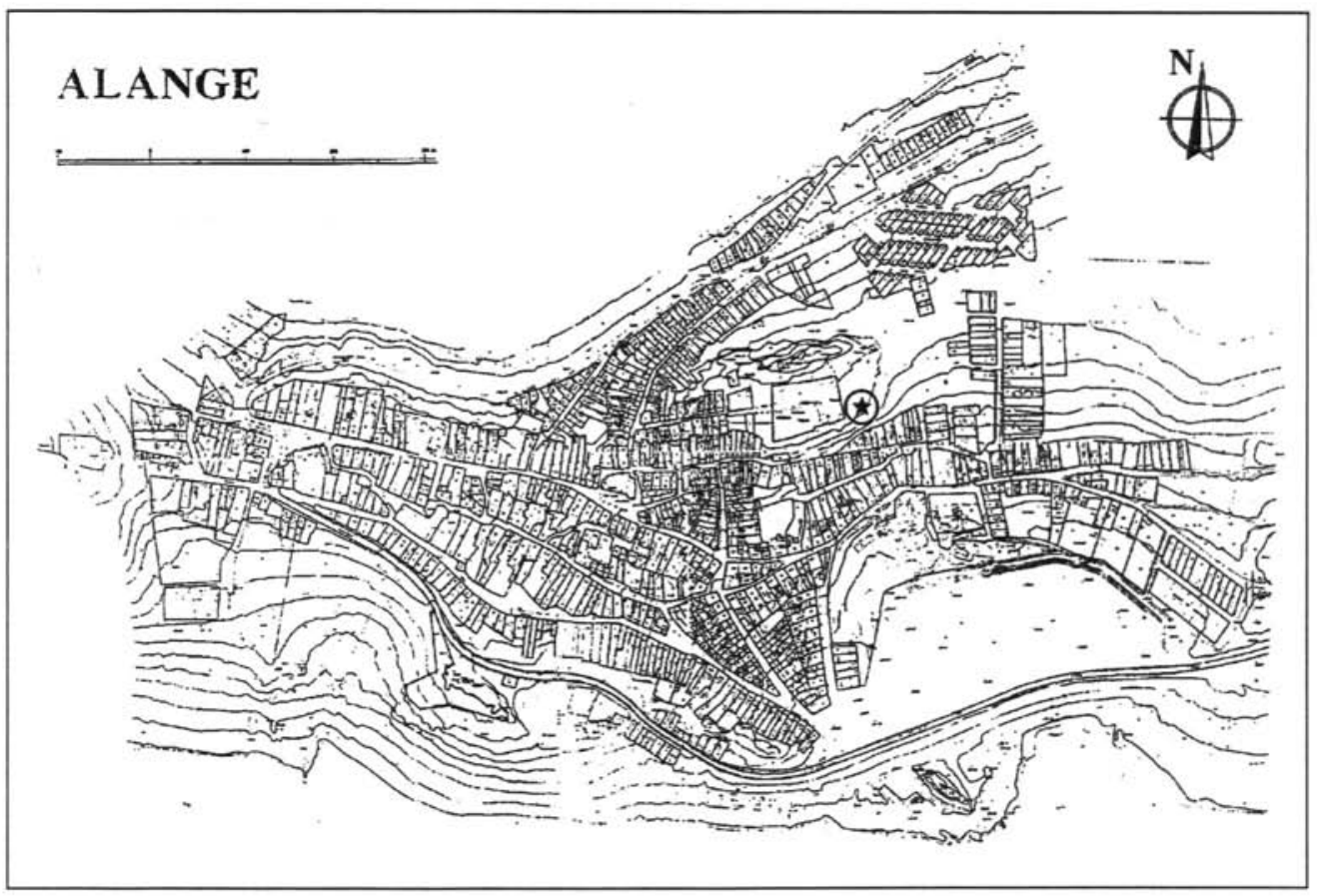

Figura 3. Plano de Alange y ubicación de los materiales recuperados en el castro de La Mesilla.

\section{LOS MATERIALES ARQUEOLÓGICOS}

De un extenso conjunto de varios millares de fragmentos se han seleccionado en torno a unas quinientas piezas que resultan especialmente apropiadas para acometer un estudio global del sitio. Se trata de una muestra (constituida por lo que comúnmente se entienden como "fragmentos dibujables") que creemos suficiente para trazarnos, a grandes rasgos, la naturaleza de una ocupación protohistórica que estimamos muy personalizada a partir de la definición, tecnológica y tipológica, de los vasos cerámicos. Así, un somero recorrido por los perfiles tecnológico y tipológico de dicho material será suficiente para plantear una primera adscripción cronológica y cultural del yacimiento.

En el conjunto de vasos documentado, las distintas producciones cerámicas ofrecen un comportamiento diferencial, en el que, de entrada, sobresale el predominio de las torneadas $(62,36 \%)$ sobre las modeladas $(37,64 \%)$. Entre las primeras, pueden distinguirse tres 

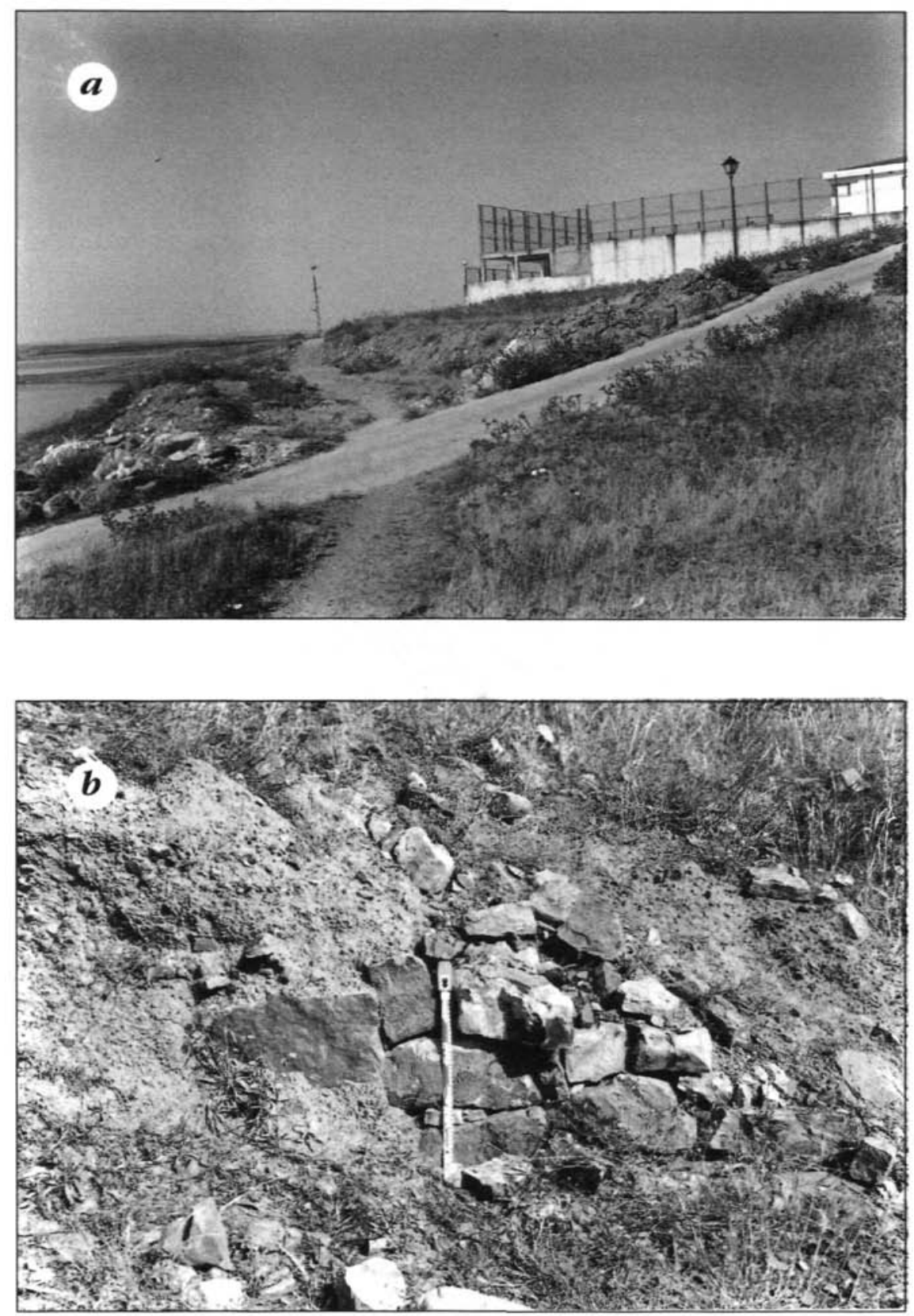

Figura 4. Estado actual de La Mesilla (a) y restos de estructuras visibles (b). 
grandes familias: las producciones grises $(3,16 \%)$, las oxidantes $(10,5 \%)$ y las toscas $(48,31 \%)$. También están presentes en la muestra, aunque de una forma muy residual, las fusayolas $(0,39 \%)$. Tanto entre las producciones a mano como entre las a torno existen ejemplares decorados cuya observación, al margen de que cuantitativamente no resultan dominantes en ninguna de las familias, proporciona también argumentos para una correcta valoración de la ocupación (figura 5).

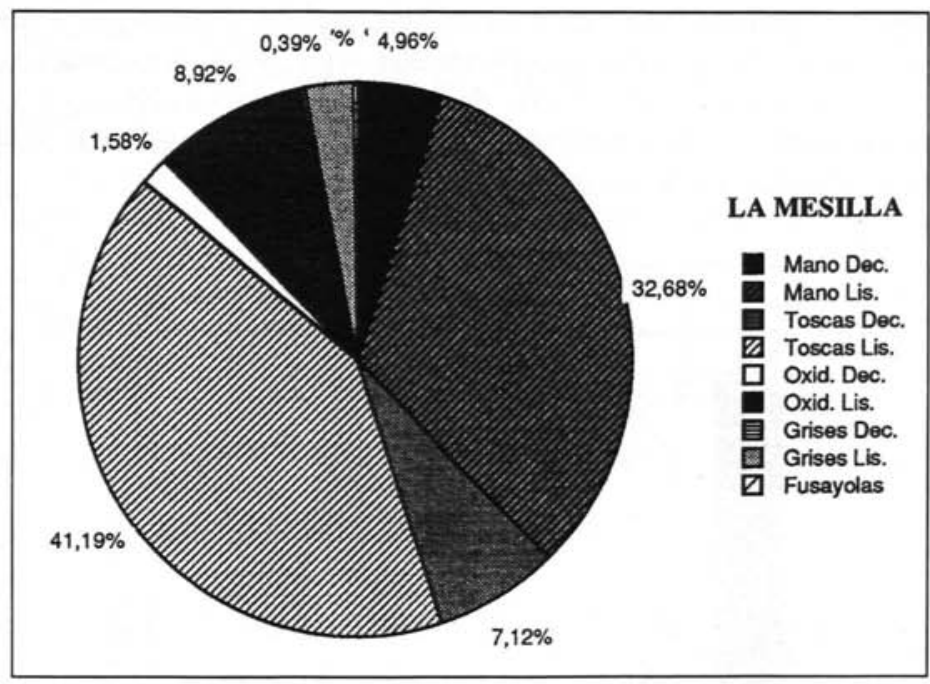

Figura 5. Comportamiento de las distintas producciones cerámicas documentadas en La Mesilla.

\subsection{Cerámicas a Mano}

Como ya se ha anticipado, las producciones a mano desempeñan un importante papel entre los materiales cerámicos recuperados, hasta el punto de representar más de un tercio de los mismos. Conocemos ejemplares tanto lisos (32,68\%) como decorados (4,96\%), en una tendencia de predominio de los primeros que no resulta extraña en el contexto general de los yacimientos del Hierro II mejor conocidos en la provincia (Rodríguez Díaz, 1987: 650689).

A grandes rasgos, pueden advertirse, pues, dos grupos en cuanto a comportamiento tecnológico se refiere. Por una parte, el constituido por vasos de cocción irregular, acabados groseros o simplemente alisados, y pastas oscuras con desgrasantes medios y gruesos, que se incluyen entre las producciones lisas. Y por otra, el que muestra cocciones principalmente reductoras, con acabados más cuidados, espatulados e incluso bruñidos, de pastas más decantadas y presencia de ornamentación en no pocos casos. Ambos permiten esbozar una tipología general de las producciones a mano que habla por sí sola de las relaciones culturales en que participa el yacimiento. 


\section{1.a. Morfología}

Los vasos elaborados a mano de La Mesilla son susceptibles de agruparse en nueve formas principales, que admiten variantes y subvariantes en función de la propia morfología o de su tamaño (figura 6). No obstante, algunos fragmentos de bases no pueden adscribirse, de entrada y a causa de la fragmentación, a ninguna de esas nueve formas principales, o bien pueden hacerlo a más de una, motivo por el cual se han excluído del recuento estadístico ocupando un lugar específico. Al margen de la descripción, seguidamente ofrecemos una valoración preliminar de su presencia en el yacimiento - que debe contemplarse con una cierta cautela, toda vez que se trata del estudio de una muestra de superficie- y un intento de contextualización a partir de la contrastación con las tipologías posiblemente más afinadas de cultura material prerromana en el sur de Extremadura.

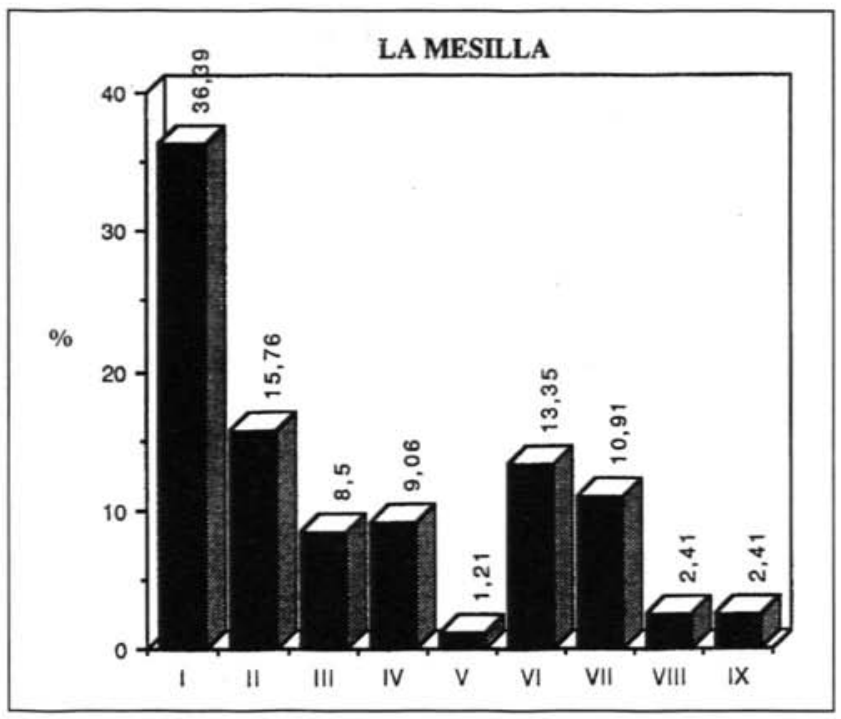

Figura 6. Formas cerámicas a mano de La Mesilla.

- La Forma I: engloba un conjunto de vasos cerrados con perfil en "S", en los que la parte superior del recipiente resulta muy corta en relación a la inferior, el cuerpo es globular y la base se adivina plana o ligeramente cóncava. Presenta un tamaño medio y un diámetro oscilante entre 11 y $21 \mathrm{~cm}$. que aconsejan incluirlas en el concepto de ollas. Podría distinguirse una variante con perfil suave y cuello cóncavo (IA), de otra con el hombro más marcado por una carena y el cuello cóncavo (IB1) o recto (IB2). Esta forma se desarrolla sobre todo entre las producciones a mano más cuidadas, llegando a acoger en algunos casos decoraciones incisoimpresas que analizaremos más adelante (figura 7). No se trata de un perfil desco- 
nocido en la protohistoria regional, puesto que ha sido recogido en las tipologías de referencia más importantes ofrecidas para el Hierro II por algunos de los yacimientos definitorios de dicho horizonte en la mitad oeste de Badajoz, como sucede en La Ermita de Belén (forma IIB y C) (Rodríguez Díaz, 1991a: 42) y en el Depósito A de Capote (formas IV y V) (Berrocal, 1994a: 155 y 159), entre otros contextos (Rodríguez Díaz, 1987 y 1989; Berrocal, 1992). En ambos yacimientos se trata de la forma a mano más numerosa (Rodríguez Díaz, 1991a: 43; BerRocal, 1994a: 154 y 160), circunstancia que se repite igualmente y de una forma destacada en el castro de La Mesilla (donde supone el 36,39\% de los perfiles a mano identificados).

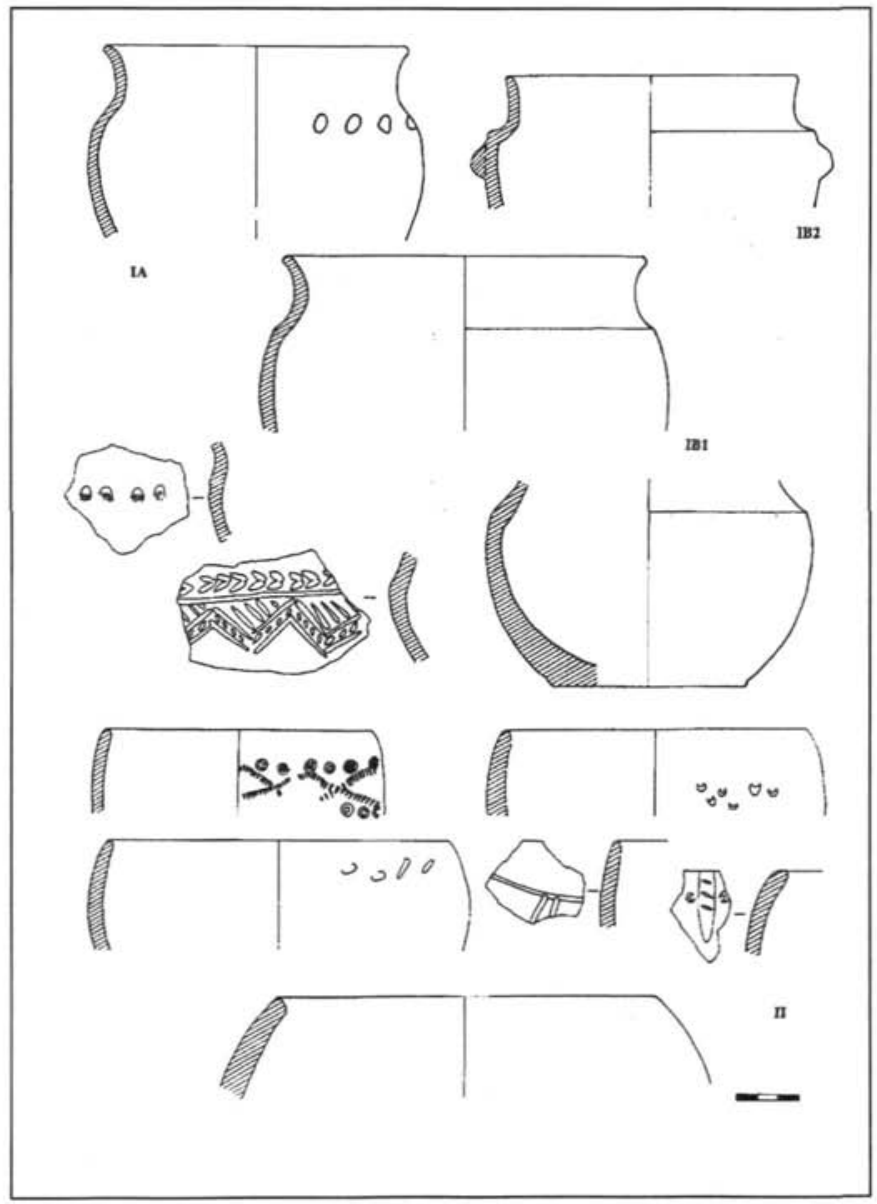

Figura 7. Formas cerámicas a mano de La Mesilla (I y II). 
- La Forma II: es otro de los perfiles más destacables del yacimiento, tanto por su relativa abundancia (se convierte en la segunda forma a mano más abundante de la muestra, con el $15,76 \%$ ), como por acoger también sobre su superficie diversas ornamentaciones inciso-impresas. Podría definirse como el vaso cerrado de perfil redondeado o globular que responde al concepto de olla o vaso de paredes entrantes, presumiblemente de base plana. En función de los diámetros con que se documenta en el conjunto que estudiamos, que van desde los $11 \mathrm{a}$ los $18 \mathrm{~cm}$., podría hablarse de sendas versiones de tamaño pequeño (II.p) y mediano (II.m), que se distinguen a su vez por la mayor calidad de pastas y tratamientos, con cocciones reductoras, en las primeras; frente a un aspecto general más descuidado, y en todo momento carente de decoración, en las segundas (figura 7). Se trata de una forma ya plasmada en las tipologías de Belén (forma I) y Capote (variante de la forma III), al margen de otros enclaves del Suroeste, entre los que cabe destacar el de Garvão (BEIRÃo y otros, 1985: 62).

- La Forma III: es un vaso igualmente cerrado y de tendencia globular, pero ligeramente estrangulado, con el cuello entrante o recto, y unas dimensiones tan dispares en el diámetro (entre 4 y $18 \mathrm{~cm}$.) que permiten diferenciar una versión muy pequeña (III.p) de otra mediana (III.m). En cualquier caso, no se destaca por su aspecto cuidado, sino por la irregularidad de cocciones, pastas y acabados, así como por ser un perfil siempre liso (figura 8). Además, es una forma con menor representación que las anteriores $(8,5 \%)$ y una definición más nebulosa en las tipologías de Belén (IIA) y Capote (podría considerarse una variante de las formas III, IV y VII).

- La Forma IV: se nos muestra como un vaso de tendencia globular y perfil en "S" (como sucedía con la forma I), pero realizado en calidades más bien descuidadas, con barros poco decantados y cocción en atmósferas más irregulares; aspectos técnicos que, junto al mayor grosor de pastas y peor resolución general, nos invitan a separarlo del mencionado perfil, conceptuándolo más bien como un cubilete u orza, según tamaños. En algunas tipologías, sin embargo, no se le ha distinguido en demasía del perfil anterior (juntos definen la forma IIB de Belén). A pesar de no resultar una forma muy abundante en esta muestra (alcanza el 9,06\%), sí se contempla bajo sendas variantes y versiones. Cabe hablar, pues, de variantes con el perfil menos (IVA) o más (IVB) marcado, y versiones en tamaño pequeño (p) o mediano $(\mathrm{m})$, según diámetros comprendidos entre 8-12 0 17-21 cm. Excepcionalmente puede presentar decoración a base de motivos impresos (figura 8).

— La Forma V: resulta imposible de reconstruir, a causa de la fragmentación sufrida por el conjunto que estudiamos, pero nos alerta de la más que posible existencia de los denominados "quemadores" o "vasos calados", de perfil cerrado, como los que encontramos en la forma III de Belén (Rodriguez Díaz, 1991a: 42), Capote (Berrocal, 1994 a: 90), Garvão (Beiräo y otros, 1985: 65), etc. (figura 8). En la Mesilla es el perfil menos frecuente (tan sólo representa el 1,21\%). 


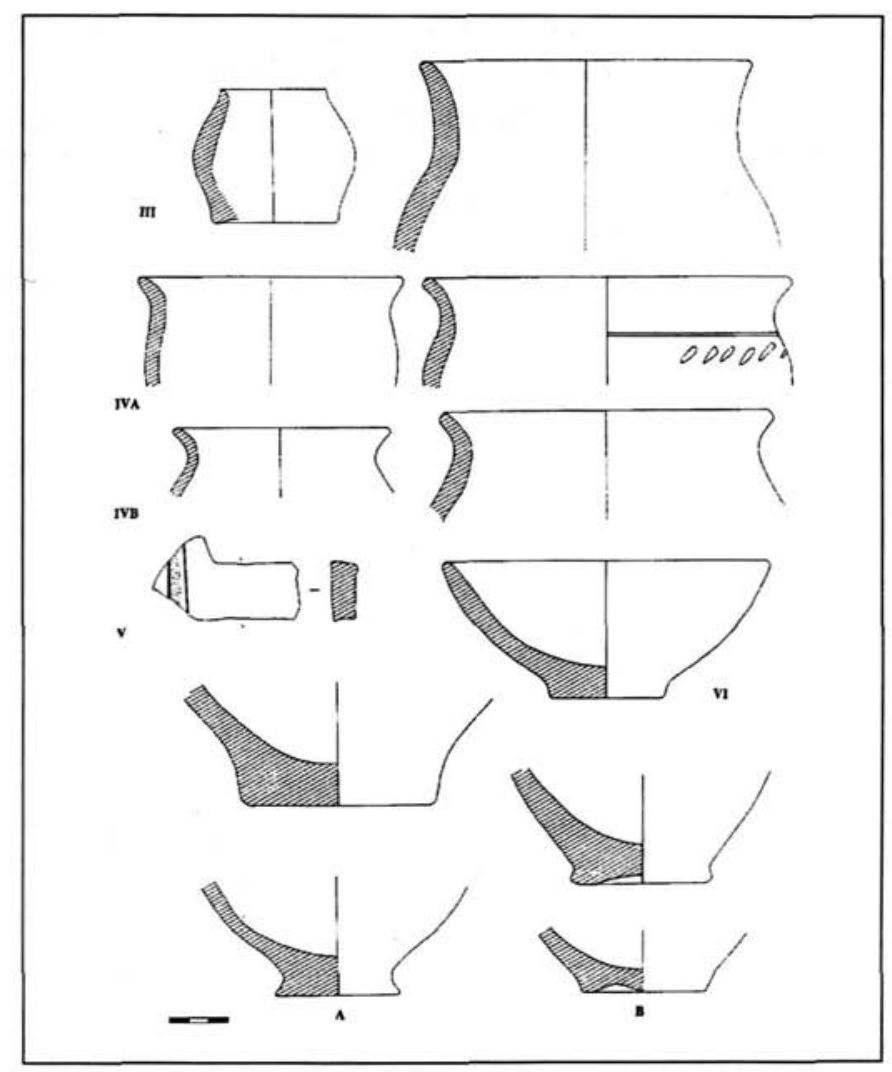

Figura 8 Formas cerámicas a mano de La Mesilla (III a VI).

— La Forma VI: se define como un cuenco con borde simple, cuerpo hemiesférico o de tendencia recta y base con fondo plano o pie indicado. Se trata, por tanto, de una forma abierta. Desde el punto de vista tecnológico predominan las pastas poco cuidadas y de cocciones reductoras, sin decoración (figura 8). Su diámetro ronda en torno a los $15 \mathrm{~cm}$. y no es sólo una forma apuntada en las tipologías más completas, como las de Belén (forma VIII) o Capote (forma II), sino también una de las mejor representadas en otros puntos de la Baja Extremadura (RoDríguez Díaz, 1987 y 1989) y, por supuesto, entre los perfiles modelados de la muestra de La Mesilla $(13,35 \%)$.

— La Forma VII: es una forma abierta y lisa que acoge a los platos o fuentes, generalmente poco cuidados y cocidos en atmósferas irregulares, entre los que resulta posible establecer diversas variantes. Por una parte, encontramos aquellos ejemplares (VIIA) que presentan un borde engrosado y un cuerpo redondeado, de escasa altura y amplio diámetro, de entre 20 y $35 \mathrm{~cm}$. Por otra, cabe diferenciar aque- 
llos recipientes que disponen de un borde recto o redondeado, pared recta con inclinación diversa y base plana (VIIB); cuyo perfil recuerda al de las escudillas, pero que, para el caso que estudiamos, presenta diámetros mucho mayores, de entre 25 y $40 \mathrm{~cm}$. Finalmente, podría incluso establecerse una tercera variante (VIIC), en función de la posesión de un borde ligeramente saliente, aunque estadísticamente muy poco representativa (figura 9). La forma VII, que globalmente está muy bien representada al suponer el 10,91\% de los vasos a mano, está también recogida en la tipología de Belén, en la que cabe reconocer tanto las variantes A y C (englobadas en la forma IV del yacimiento zafrense), como la B (similar a su forma IX).

- La Forma VIII: resulta muy difícil de definir, puesto que su perfil nunca se nos ha conservado completo. Es, en cualquier caso, un vaso abierto, de mediano tamaño, realizado en pastas no especialmente cuidadas ni en la cocción ni en el acabado, jamás decorado, y que presenta un borde saliente o exvasado y destacado del cuerpo. Con un perfil en " $Z$ " o en " $S$ ", según la presencia o no de carena, da lugar a sendas variantes (VIIIA y VIIIB) (figura 9). A partir de ahí, podríamos especular con la existencia de una base plana, o incluso un perfil piriforme y un fondo inestable, que lo acercarían ya a las cazuelas (contempladas en la tipología de la Ermita de Belén como forma V), ya a otros vasos utilizados presumiblemente para el almacenaje (del tipo de las reconstrucciones que perfilan la forma VI de Capote). Su presencia en la muestra que venimos considerando es muy poco destacable, al suponer tan sólo el 2,41\% de los vasos a mano.

- La Forma IX: está también muy mal representada, con una frecuencia de documentación similar a la del vaso anterior. Incluye todos aquellos fragmentos que pertenecieron a tapaderas, bien en una variante con orificio de salida de vapor (IXA), o bien en otra vertiente más canónica, con aplicaciones para su agarre (IXB) (figura 9). Se trata de un perfil reconocido implícitamente en yacimientos como los de Belén, Capote, la Alcazaba de Badajoz (EnRíquez y otros, 1998: 182), etc.

Tal y como se ha expresado anteriormente, además de los fragmentos susceptibles de incluirse en las formas anteriores, se encuentran un buen número pertenecientes a bases de recipientes difícilmente identificables. Se trata de bases ya planas (tipo A), ya cóncavas o con pies ligeramente indicados (tipo B), que se reparten de una forma aparentemente equitativa (figura 8).

\section{1.b. Decoración}

Entre las producciones modeladas, los vasos decorados suponen un grupo bastante poco numeroso que apenas alcanza el $5 \%$ de dicha familia. Aún así, ha de reconocerse, y dentro de una gama ciertamente corta de técnicas ornamentales, especialmente inciso-impresas, una relativa variedad de motivos aplicados siempre al exterior, en ocasiones bastante vistosos, que nos remiten, una vez más, a los mismos enclaves referenciales ya aludidos en el apartado morfológico. 
Nos encontramos con impresiones ovales, parecidas a pequeñas digitaciones, desarrolladas sobre una zona elevada del galbo de la forma IA, similares a las documentadas en Belén (Rodríguez Díaz, 1991a: 47) y en Capote (BerRoCAL, 1994a: 96); impresiones a punzón que reproducen motivos de media luna u oquedades, similares a otros de Belén y Capote (BERROCAL, 1994a: 98), aunque aquí sobre vasos de la forma II.p, complementados a veces con tirillas verticales que reciben idéntica decoración; ungulaciones, impresiones a punta de navaja o de espátulas rectangulares y curvas, e incisiones, similares, una vez más, a las tipificadas en Belén y Capote (BErrocal, 1994a: 96, 99, 100 y 121), a veces conviviendo en la misma pieza, sobre la parte superior de los galbos de las formas IA, II.p y IV.m; e impresiones "compuestas", donde se combinan verdaderos motivos estampillados circulares y radiales con impresiones a peine, bien conocidos ambos en Capote (BERROCAL, 1994a: 101 y 108), como sucede en La Mesilla sobre un ejemplar de la forma II.p. Finalmente, podría referirse la existencia de motivos realizados con incisiones profundas o acanalados, a veces combinados

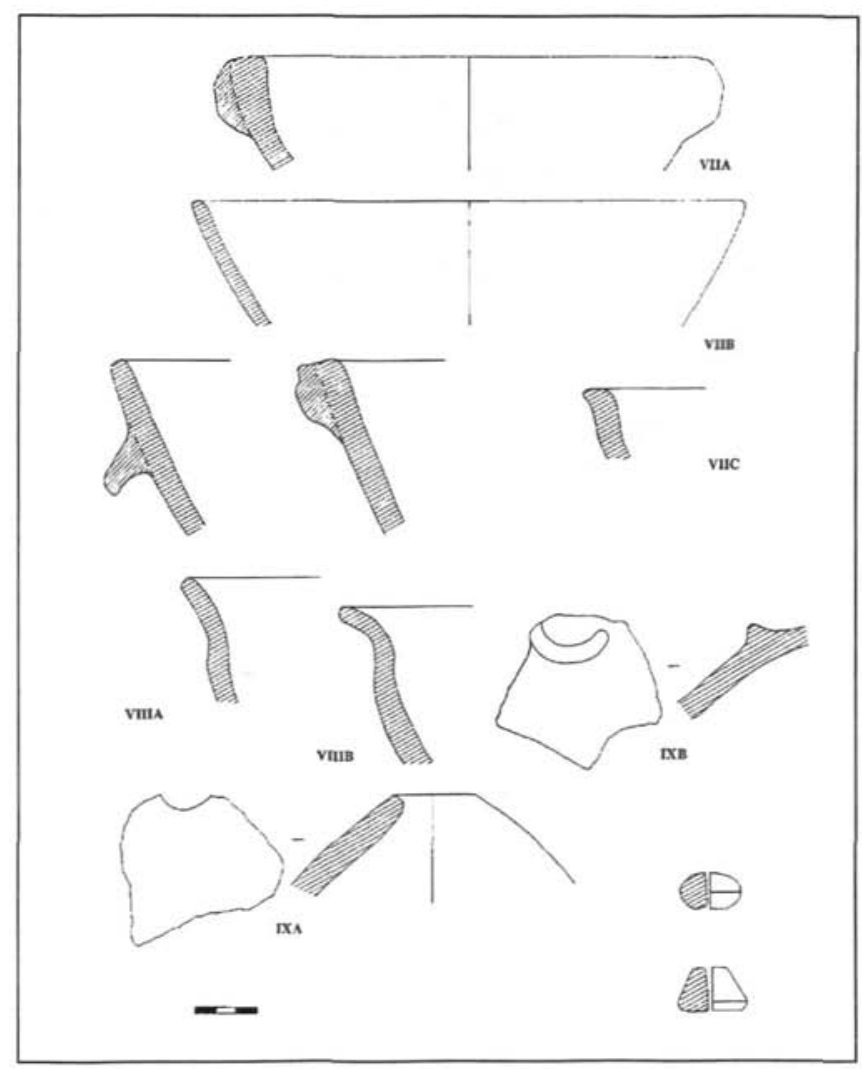

Figura 9. Formas cerámicas a mano de La Mesilla (VII a IX). 
con otras incisiones que reproducen espigados u hojas de acacia, ya tipificados en nuestra región en Belén (Rodríguez Díaz, 1991a: 16) y en Capote (Berrocal, 1994a: 123 a 128), que generan decoraciones barroquizantes sobre las formas IA y II.p (figuras 7 y 8 ).

Si tuviéramos que proceder a una valoración preliminar del yacimiento en función de la producción modelada, sin duda lo haríamos aludiendo a la identidad que manifiestan los vasos de La Mesilla con algunos de los plasmados en las tipologías de los yacimientos pacenses de la Ermita de Belén (Zafra), y el Castrejón de Capote (Higuera la Real), donde son considerados elaboraciones locales - a veces con remotas raíces, tal vez en un Bronce Final de sabor atlántico (BERROCAL, 1992: 105 y 1995: 171), realmente difíciles de demostrar (PAVÓN, 1995: 900 a 958) - destinadas a cubrir necesidades funcionales en relación con la cocina y el almacenaje de alimentos. En estos enclaves, y en otros puntos del suroeste peninsular para los que ambos yacimientos constituyen, tal vez, la mejor referencia estratigráfica, dicha producción vascular contribuye notablemente a la definición y al reconocimiento de una cultura material vinculada a la Segunda Edad del Hierro cuyo desarrollo se adscribe a los siglos IVIII y, posiblemente, II a.C. (Rodríguez Diaz, 1987 y 1989; Berrocal, 1992). En determinados casos puntuales, como sucede en la Alcazaba de Badajoz, donde, por circunstancias igualmente particulares, se ha fosilizado el paso del tiempo de una forma excepcional, resulta sintomático advertir un resurgimiento de las producciones modeladas precisamente en estos momentos (ENRíQuez y otros, 1998: 178). Desde esta perspectiva puede entenderse bastante bien la importante representación -tipología y ornamentaciones al margen- de esta familia en la muestra de La Mesilla.

Respirando el mismo aire que estas manifestaciones bajoextremeñas, aunque con algunas variantes propias de la diversidad regional, ya señaladas por la investigación, habría que apuntar hacia el Horizonte Cultural Posthallstáttico de la Meseta Norte -conceptualizado como Protoarévaco, Protovacceo, o Cogotas IIa- (ROMERO, 1984) para encontrar un marco global con el que paralelizar la morfología y ornamentación de estos materiales. Sin embargo, una contextualización más afinada de los mismos pasa por subrayar, siguiendo igualmente trabajos precedentes (RoDrígufz DiAz, 1987: 670), su inclusión dentro del ambiente general que personaliza a dicha etapa en buena parte del mediodía portugués, especialmente alentejano, el Ferro II Continental (Coelho y VARELA, 1992: 172-3), y que parece englobar también a buena parte del occidente de la Baja Extremadura en el ámbito del "Círculo Céltico" (Rodríguez Diaz, 1987 y 1989; Berrocal, 1992). Recientemente se ha llamado la atención precisamente sobre un estilo de las cerámicas a mano cuya simbología permite llegar a considerarlas como étnicamente "emblemáticas" (BERROCAL, 1995: 170). No obstante, su aparición en algunos puntos de la Media Extremadura, como los castros vettones de Botija (Hernández y otros, 1989) y La Coraja (Esteban OrTEGa, 1993), invitan a matizar, al menos, esas expectativas generadas en torno a las posibilidades de utilización de esta cerámica como marcador étnico.

\subsection{Cerámicas a Torno Grises}

La cerámica gris constituye una familia que, tal y como se ha expresado anteriormente, aparece minoritariamente representada en la muestra recuperada en La Mesilla. De ella, el $2,77 \%$ pertenece a ejemplares lisos, frente a un reducido $0,39 \%$ de fragmentos decorados. Nos 
encontramos, pues, ante una cuantificación bastante equiparable a la de la producción vascular gris de la fase IVB en el corte "Sector Puerta de Carros-2" de la Alcazaba de Badajoz, fechable entre el 350 y el 150 a.C., donde supone un residual 3,6\% (ENRíQuEz y OTROs, 1998: 185); aparición minoritaria que se repite, una vez más, en el poblado de Los Castillejos- 2 de Fuente de Cantos (Rodríguez Díaz, 1987; Fernández y otros, 1988). También en el Corte 1 de la Ermita de Belén ocupan, porcentualmente, el tercer lugar de los vasos torneados, tras las producciones oxidantes y las toscas, aunque con un mayor porcentaje $(14,94 \%$ de lisas y $0,54 \%$ de decoradas), y una presencia especialmente significativa en la fase II, fechada entre el pleno siglo III y comienzos del II a.C. (Rodríguez Díaz, 1991a: 69-70). En otros contextos prerromanos extremeños que aportan datos cuantificables, como La Martela o el Cantamento de La Pepina, estudios particulares de esta modalidad cerámica han puesto de manifiesto un comportamiento numérico, a grandes rasgos, similar (HERNÁNDEZ CARRETERO, 1996: 38 y 6566). Tan sólo las informaciones referentes a la fase IVB de Medellín, que se viene fechando hacia el siglo IV a.C., documentadas en el Corte 2 de la Ladera Norte apuntan, en el marco de una tendencia declinante de esta producción, unos registros ligeramente más altos, por encima del 20\% (ALMAGRO y MARTín, 1994: 92 y 109), cuya interpretación, en el panorama general esbozado, no resulta exenta de problemas.

Así las cosas, tampoco resulta extraño que las características que presentan los fragmentos que ahora estudiamos no difieran de las hasta ahora conocidas: pastas bien depuradas, con desgrasantes finos, colores oscuros, cocciones reductoras y tratamientos superficiales relativamente cuidados.

Los escasos fragmentos decorados, que no han podido adscribirse a ninguno de los perfiles que seguidamente veremos, presentan motivos estampillados troquelados, realizados muy posiblemente mediante matrices parecidas a las ya documentadas tanto en Belén (Rodríguez Díaz, 1991a: 66) como en algunos poblados alentejanos (ARNAud y Júdice Gamito, 1974-77: 166). Se trata de manifestaciones que podrían incluirse sin problemas en los estampillados del Tipo II de la Baja Extremadura (Rodríguez Díaz, 1987: 785). Desde el punto de vista morfológico, tampoco resulta una muestra especialmente compleja, puesto que sólo se han recuperado ejemplares pertenecientes a dos formas abiertas y una tercera cerrada (figuras 10 y 11$)$ :

- La Forma I: podría definirse como el plato de paredes rectas o hemiesféricas y borde de tendencia más o menos vertical, con carena, que parece imitar la forma Lamboglia 5 de los perfiles de la Campaniense B. Aquí su diámetro supera los 12 $\mathrm{cm}$. (figura 11). Se trata de un vaso muy poco representado en la muestra, pero que parece abogar por una ocupación del yacimiento al menos hasta el siglo II a.C., si tenemos en cuenta los contextos en que aparece en Capote, La Pepina, Hornachelos o Miróbriga (Hernández, 1996: 124).

- La Forma II: incluye a los cuencos, o perfiles abiertos en forma de casquete, con borde redondeado (IIA) o ligeramente apuntado (IIB) y base tal vez cóncava o anular con pie indicado. Sus diámetros rondan los 13-14 cm. (figura 11). Algo mejor representada que la anterior (con un $2,18 \%$ de las producciones a torno), es de hecho la forma más abundante entre las producciones grises en diversos yacimientos prerromanos pacenses, entre los que resulta un buen botón de muestra 
Belén (Rodríguez DiAz, 1991a: 65). Hunden sus raíces en la tradición de los cuencos grises de sabor orientalizante, y poseen su trasunto en las producciones oxidantes (HERNÁNDEZ, 1996: 110). El valor tipológico y cronológico de las variantes de La Mesilla, como sucede en los demás enclaves donde se han detectado, es realmente escaso.

- La Forma III: es un vaso de perfil en "S", posiblemente una forma cerrada calificable como urna, con una base presumiblemente umbilicada (figura 11). No es un tipo nada abundante, aunque tampoco desconocido en contextos del Hierro II bajoextremeño (Rodríguez Díaz, 1989: 194). En la Ermita de Belén aparece contemplado como forma III (RoDríguez DiAz, 1991 a: 62).

$\mathrm{Ni}$ que decir tiene que la familia de las cerámicas grises prerromanas, que ahora analizamos, arranca de una tradición remontable en el mediodía peninsular al período Orientalizante (BELÉN, 1976; CARO, 1989) y desemboca en una serie de perfiles que, desde el siglo III hasta la romanización, no son sino nuevas versiones y nuevas formas compartidas en el marco general del Suroeste (Hernández, 1996). En este sentido, tanto la progresiva diferenciación de unos tipos específicamente prerromanos (ESCACENA, 1987; RODríguez Díaz, 1987: 736-749; 1991a: 67), casi siempre también familiares en las producciones oxidantes -una vez superado el panorama inicial de desconocimiento de estas producciones en Extremadura para los siglos IV-I a.C.-, como el argumento de silencio que supone la ausencia de determinados perfiles de sabor claramente oriental, inciden positivamente en una más afinada adscripción de materiales que, como éstos de La Mesilla, entran a formar parte de una forma discreta en muestreos globales donde poseen mayor protagonismo otras producciones.

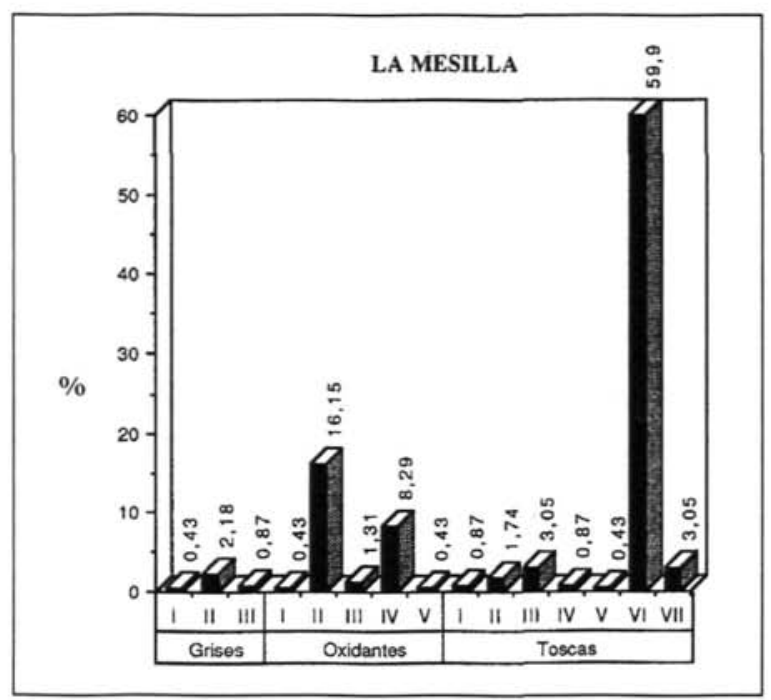

Figura 10. Formas cerámicas a torno de La Mesilla. 


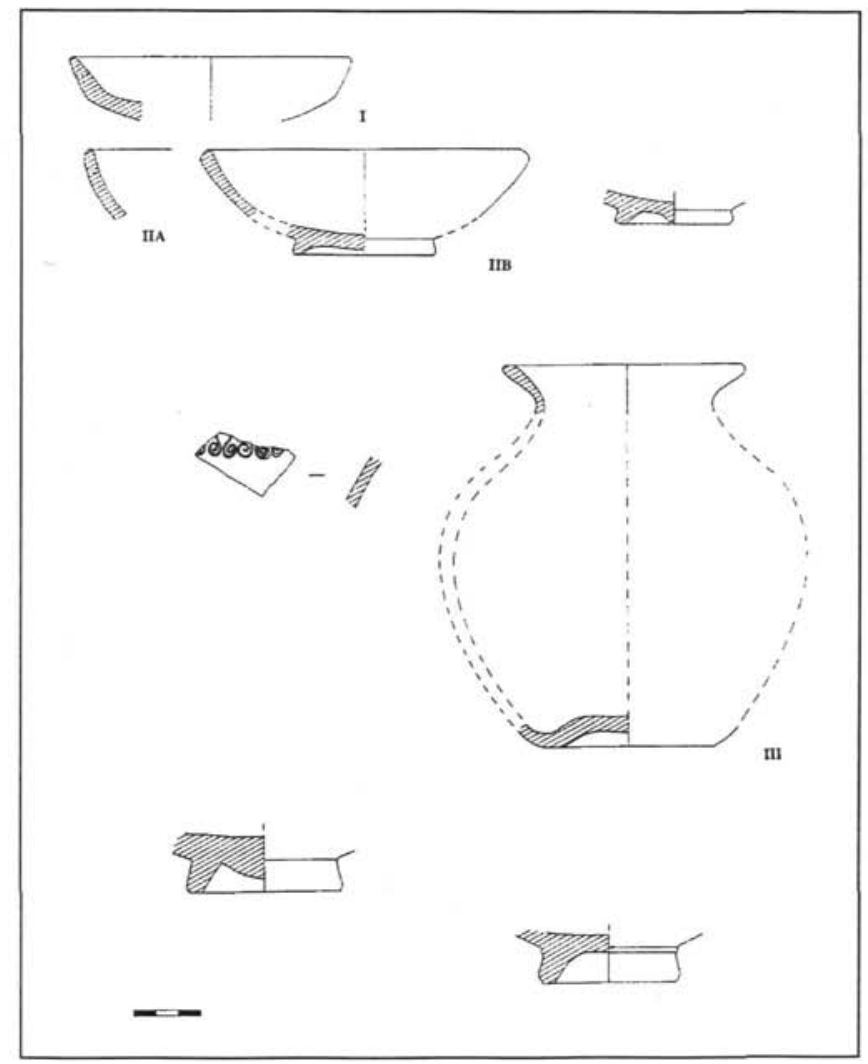

Figura 11. Cerámicas a torno grises de La Mesilla.

\subsection{Cerámicas a Torno Oxidantes}

Constituyen una familia bien representada en la muestra alangeña, en la que los ejemplares lisos $(8,92 \%)$ superan a los decorados $(1,58 \%)$. En el contexto general bajoextremeño del Hierro II, como en el caso que estudiamos, las cerámicas a torno oxidantes no sólo son conocidas, sino que constituyen uno de los grupos que, dejando a un lado las producciones a torno toscas, están más sólidamente definidos (Rodríguez DiAz, 1987: 690-735; 1989: 187). De hecho, el global de los conjuntos estudiados muestra un arco cuantitativo que va desde el 18,8\% de La Pepina (Rodríguez y BERROCAL, 1988), hasta el 59,10\% de la fase IVB del Corte 2 en la Ladera Norte de Medellín (Almagro y Martín, 1994: 94); no faltando casos, como sucede en Belén, donde constituye el tipo cerámico más abundante, con un 36,12\% (RODRíguEz DíAz, 1991a: 51). En este contexto de progresivo protagonismo de las producciones oxidantes, en detrimento de las grises, hay que entender, tal vez, la transición de unos mismos perfiles cerámicos desde la familia declinante a la otra pujante. 
Como puede intuirse a partir de la tipología documentada y de las características de fábrica, estas cerámicas debieron configurar una vajilla utilitaria, empleada en tareas domésticas como complemento de los tipos restantes. Con pastas más o menos depuradas, tonalidades anaranjadas o rojizas, acabados simplemente alisados en la mayoría de las ocasiones -y no pocos matices tecnológicos que invitarían a plantear una posible, aunque complicada, subdivisión interna- se consideran hoy por hoy como una producción eminentemente local. Los pocos ejemplares decorados, a base generalmente de motivos geométricos lineales (bandas y círculos concéntricos) en pintura monócroma con tonalidad rojiza vinosa, pueden relacionarse, a grandes rasgos, tanto con las producciones del Valle del Guadalquivir (EsCACENA, 1979-80; BelÉn y Perfira, 1985; Pereira, 1988 y 1989), como con otras progresivamente documentadas en zonas más septentrionales de Extremadura (CABELLO, 1991-92), aunque resultan también cada vez más familiares en los yacimientos prerromanos de la Baja Extremadura (Rodríguez Díaz, 1987: 750-776; 1989 y 1991a; BERrocal, 1992, 1994; ENríqueZ y OTros, 1998) (figura 12).

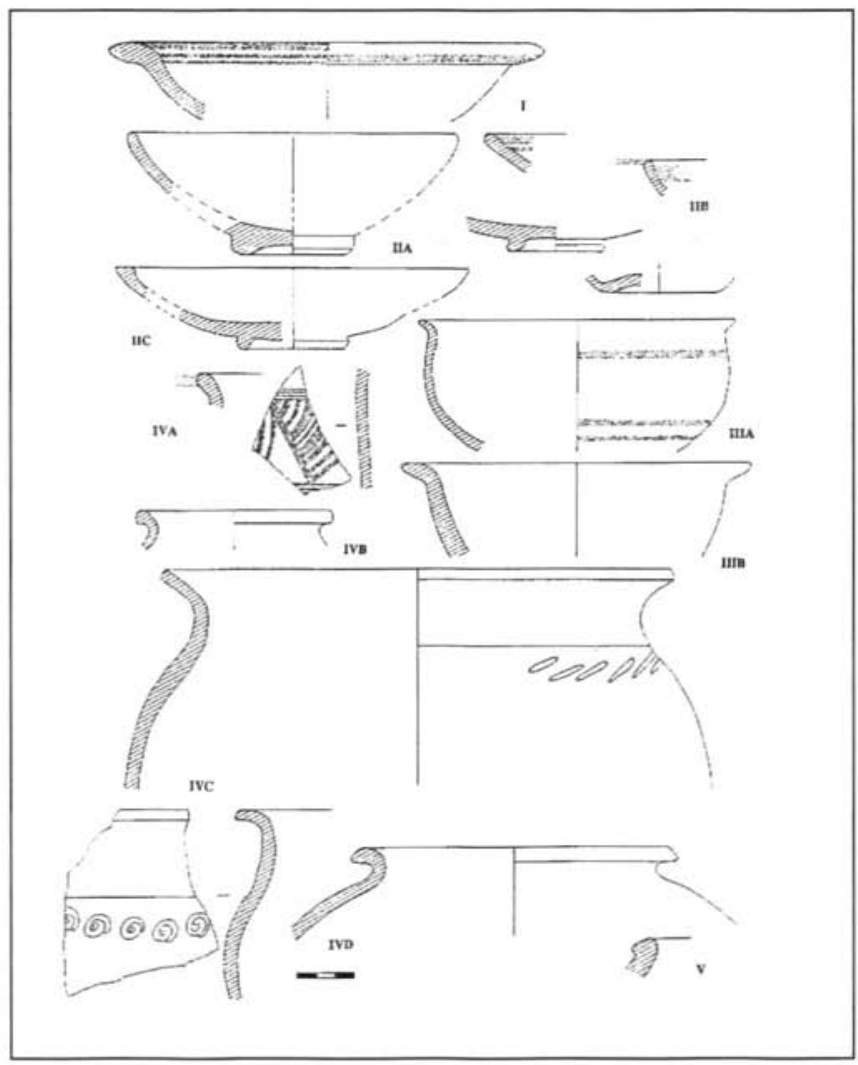

Figura 12. Cerámicas a torno oxidantes de La Mesilla. 
Son cinco las formas que pueden distinguirse entre las cerámicas cocidas en atmósferas oxidantes de La Mesilla, con un porcentaje de aparición muy desigual y una marcada tendencia a la producción de ejemplares de mediano tamaño (figura 10). Aunque frecuentemente se han documentado fragmentos de grandes vasos -vasijas de almacén- con idéntica cocción, los tratamientos más descuidados de sus superficies aconsejan que los incluyamos en el apartado de las cerámicas a torno toscas.

- La Forma I: es un perfil abierto, constituido por el plato de borde saliente, sin carena, cuyo diámetro supera ligeramente los $20 \mathrm{~cm}$., y que presentaría muy posiblemente una base cóncava con pie indicado. Aparece decorado con pintura roja distribuida en bandas tanto al interior como al exterior del labio (figura 12). No se trata de un perfil desconocido en los poblados del Hierro II pacense -es la forma IXB de la tipología de Belén (Rodríguez Díaz, 1991a: 56)- aunque, como sucede en la muestra de La Mesilla, tampoco es de los más abundantes.

- La Forma II: es el cuenco o plato de cuerpo hemiesférico y base anular con el pie indicado que, en función del aspecto del borde -redondeado (A), apuntado (B), o almendrado (C) - es susceptible de contemplarse bajo distintas variantes. En los ejemplares documentados presenta un diámetro oscilante entre los 17 y $20 \mathrm{~cm}$., y en ocasiones ornamentación pintada monócroma (roja o negra) a bandas tanto al exterior como al interior (figura 12). Es uno de los perfiles más repetidos entre los vasos torneados de esta muestra (donde suponen un 16,15\%), mostrando así esa misma tendencia al protagonismo que se advierte en otros yacimientos de la zona occidental pacense, de los que un buen ejemplo es Belén (RODRíguez Díaz, 1991a: 59).

- La Forma III: podría definirse como un cuenco con un borde de marcada tendencia exvasada, como en la forma I, pero con el cuerpo más hondo y con una base cóncava. Los ejemplares conservados (que tal vez podrían dar lugar a dos variantes) presentan un diámetro ligeramente superior a $16 \mathrm{~cm}$. y, a veces, decoración pintada roja a bandas por el exterior -bajo el cuello y en la parte baja del cuerpodel vaso (figura 12). Podría relacionarse con la forma IV2 de Belén, si bien resulta un perfil bastante más familiar entre las producciones grises bajoextremeñas (RODRíguEz DiAZ, 1989: 195, $\mathrm{n}^{2} 7$ ).

- La Forma IV: incluye distintas variantes de un mismo perfil que puede calificarse de urna o vaso de perfil en "S". Se trata, pues, de un vaso globular u ovoide, con un cuello de desigual desarrollo y un fondo seguramente cóncavo. En los ejemplares recuperados el diámetro discurre entre los 14 y $26 \mathrm{~cm}$. Las distintas variantes se establecen en función tanto de la longitud del cuello como del perfil del labio, originando tres variantes con cuello más o menos desarrollado y borde simple o redondeado (A), engrosado al exterior (B), o apunado (C); y una cuarta con borde en forma que recuerda a los de "pico de ánade" sobre un cuello de muy escaso desarrollo (D). Otro aspecto destacable es la variedad de técnicas ornamentales aplicadas sobre su superficie, que van desde la pintura a bandas rojizas en la parte exterior del labio y el barniz o engobe rojizo, hasta las impresiones a espátula, ungulaciones o estampillas con motivos concéntricos, similares a las 
documentadas sobre vasos toscos de gran tamaño (figura 12). Finalmente, resulta obligado señalar que se trata de un perfil relativamente bien documentado $(8,29 \%)$ en el conjunto de las producciones a torno de La Mesilla. Esta es una circunstancia que se repite también en algunos yacimientos bajoextremeños, como es el caso de Belén, donde sumando las frecuencias de las formas III y IV de su tipología, que son idénticas a nuestras variantes D y A, B y C, respectivamente, se advierte su presencia mayoritaria entre los vasos oxidantes (Rodríguez Diaz, 1991a: 55 y 59).

- La Forma V: resulta muy minoritaria, a diferencia de la anterior, y acoge un borde de pequeño tamaño con engrosamiento al exterior, que podría pasar tanto por un anforisco que reprodujera el perfil de ejemplares mayores (Rodríguez Díaz, 1991a: $53, n^{2} 7$ ), como por un borde de ungüentario, del tipo de los documentados en el yacimiento cacereño de La Coraja (EsteBAN, 1993: 108, a). Esta indefinición aconseja que mantengamos una extrema cautela ante su valoración (figura 12).

Siguiendo las tendencias morfológicas apuntadas por trabajos precedentes (RODRíGUEZ Diaz, 1987 y 1991a), una valoración global de las producciones oxidantes no debe concluir sin recordar la inspiración andaluza que globalmente respiran, así como el aparente carácter relativamente evolucionado del que participan los ejemplares ahora presentados, que muy bien podría sugerirnos una fechación entre los siglos III-II a.C.

\subsection{Cerámicas a Torno Toscas}

Constituyen la familia mejor representada en la muestra de La Mesilla, donde alcanza una dimensión estadística $(48,31 \%)$ comparable a la del mismo tipo cerámico en la fase IVB (Hierro II Pleno) del Corte Sector Puerta de Carros 2 en la Alcazaba de Badajoz (59,38\%) (Enriquez y otros, 1898: 184). Además, se trata del conjunto o variedad cerámica en el que, a pesar de ser predominantes los lisos $(41,19 \%)$, muestran un mayor protagonismo cuantitativo los ejemplares decorados $(7,12 \%)$, cuyo estudio estilístico mejor contribuye a definir la identidad cultural del asentamiento.

Como hemos apuntado anteriormente, una buena parte de los ejemplares que contemplamos entre las producciones a torno toscas ha sido cocida en atmósferas oxidantes -aproximadamente el $80 \%$ - lo cual explica que en determinados casos algunas tipologías hayan incluido en la familia de los vasos a torno oxidantes perfiles que nosotros preferimos englobar en el tipo cerámico que ahora tratamos. Las pastas poco depuradas y el desgrasante grueso con que se fabrican, el tamaño preferentemente grande de estas vasijas, su especial funcionalidad, y esa tendencia a mostrar un acabado mal alisado o grosero, son argumentos que justifican su inclusión en este nuevo grupo. Centremos nuestra atención, pues, tanto en las formas como en las decoraciones de un modo más detenido.

\section{4.a. Morfología}

Estadísticamente, las formas más repetidas en la tipología que nos ofrece la cerámica a torno tosca de La Mesilla nos sitúan ante producciones vinculadas especialmente a la conservación y el almacenaje que justifican sus importantes dimensiones y su perfil cerrado 
(figura 10). Sin embargo, al margen de estos perfiles -cuyo predominio resulta abrumadorse encuentran otros abiertos que enriquecen en cierto modo la tabla que presentamos:

- La Forma I: acoge a las fuentes lisas de perfil hemiesférico y gran diámetro, inspiradas muy posiblemente en ejemplares similares modelados (figura 13). No constituyen un grupo numeroso ni significativo, ni en esta muestra ni en otros yacimientos prerromanos bajoextremeños (RodríGuEZ Díaz, 1987).

- La Forma II: viene definida por los grandes cuencos de cuerpo globular y borde ligeramente saliente, con un diámetro superior a los $35 \mathrm{~cm}$. y una base no conoci$\mathrm{da}$, aunque presumiblemente plana. Nunca aparecen decorados (figura 13). Resultan bastante conocidos en el ámbito meridional peninsular, donde también se les considera fuentes (Ruzz MATA, 1987: 312). En la muestra que estudiamos no resultan muy abundantes, de la misma forma que tampoco lo son en otros yacimientos del Hierro II bajoextremeño como el de Belén (Rodríguez Díaz, 1991a: 50).

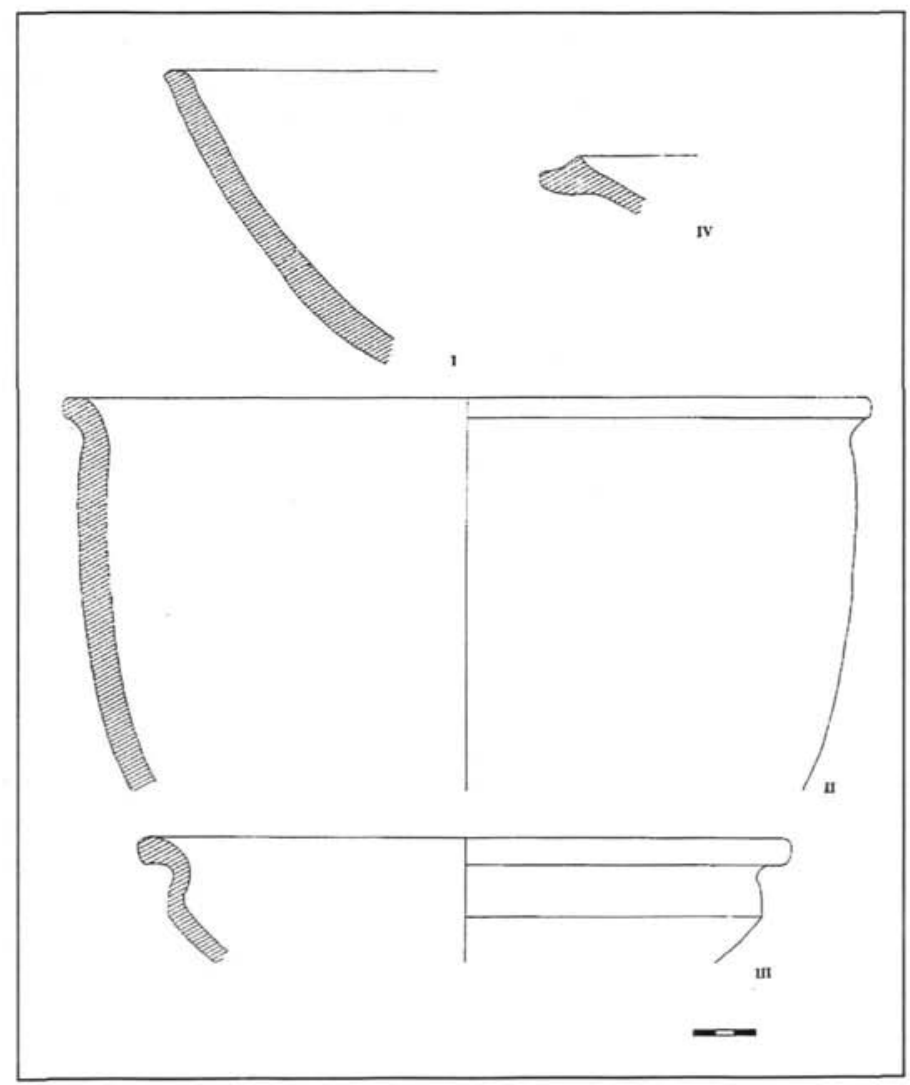

Figura 13. Cerámicas a torno toscas de La Mesilla (I a IV). 
- La Forma III: acoge diversos ejemplares abiertos que podemos considerar lebrillos o cazuelas, con diámetros considerables, de entre 30 y $50 \mathrm{~cm}$., borde exvasado, cuerpo carenado y una base posiblemente plana (figura 13). Se trata de perfiles lisos bien conocidos, no sólo en la Baja Extremadura (Rodríguez Díaz, 1991a: 49) y el Alentejo (BERROCAL, 1992: 111), sino también en el ámbito turdetano (Pellicer y OTROS, 1983: 126 y 137; RuzZ MATA, 1987: 312), y vienen a suponer poco más de un $3 \%$ en el conjunto de los vasos torneados de La Mesilla.

- La Forma IV: define a esa serie de recipientes abiertos y lisos que en la bibliografía aparecen recogidos con el nombre de morteros, y cuya funcionalidad resulta un tanto imprecisa. Presentan, en los casos alangeños, diámetros superiores a unos 30 $\mathrm{cm}$. y bordes bastante desarrollados (figura 13). Nuevamente, los mejores paralelos los encontramos, amén de en contextos republicanos bajoextremeños (RODRíGuEZ Díaz, 1987; Rodríguez y Jiménez, 1987-88: 23), en la Turdetania, donde, extendiéndose efectivamente hasta la romanización, se les hace arrancar de contextos netamente prerromanos fechables hacia el siglo IV a.C. (Ruzz MATA, 1987: 309 y 310).

- La Forma V: viene representada por el primer perfil de vasija destinada al almacén en la tipología de La Mesilla, donde, sin embargo, no resulta nada abundante. Hablamos del gran vaso liso de cuerpo globular y hombro fuertemente marcado, con un borde de tendencia vertical aunque ligeramente engrosado al interior, y boca de unos $30 \mathrm{~cm}$. de diámetro (figura 14). En un contexto Post-orientalizante como es el edificio de prestigio de La Mata de Campanario podemos encontrar los precedentes morfológicos y funcionales de esta forma (RODRíGUEZ Y ORTZ, 1998: 217), que no resulta del todo extraña en contextos prerromanos del mediodía español, según se advierte, por ejemplo, en el Cerro Macareno (PeLLICER Y OTROS, 1983: 121).

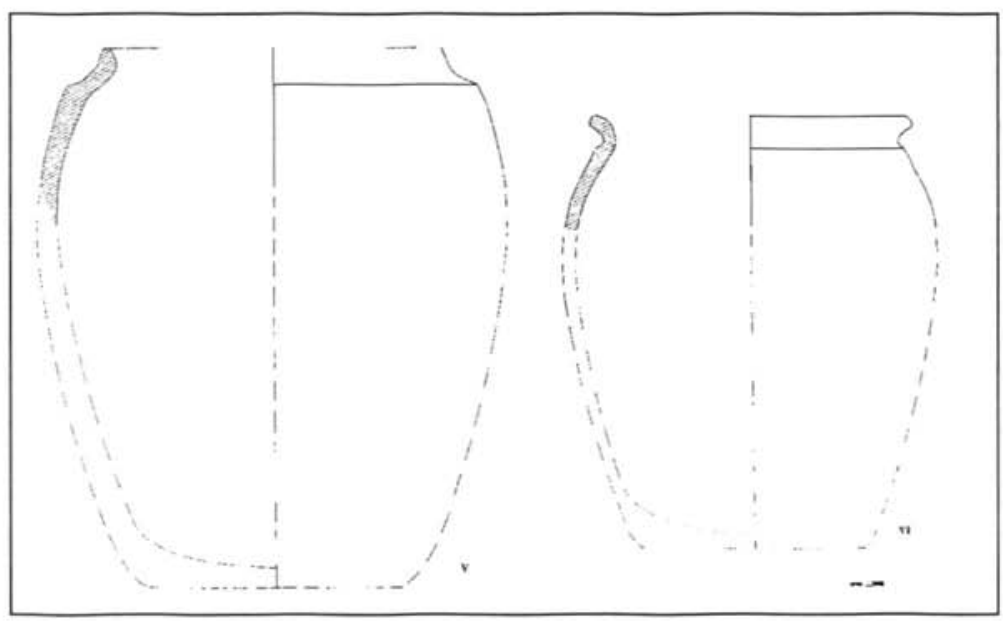

Figura 14. Cerámicas a torno toscas de La Mesilla (V y VI). 
— La Forma VI: es la vasija de almacén de grandes proporciones, con fondo plano, sección globular, cuello diversamente desarrollado y borde generalmente exvasado, cuya variabilidad interna da lugar a una compleja ramificación en variantes y subvariantes (figura 14). Sus diámetros oscilan generalmente entre los 20 y $50 \mathrm{~cm}$., aunque hay ejemplares puntuales que superan esa última cifra. En conjunto, viene a ser el vaso más representado entre las producciones torneadas de la muestra de La Mesilla, con un $59,9 \%$ del total. Además, constituyen una de las pocas formas sobre cerámica tosca que a veces recibe decoración, mayoritariamente estampilla$\mathrm{da}$, como veremos. Sus variantes, a grandes rasgos, se definen por los particularismos presentados en la región del cuello y el borde, pudiendo articularse, resumidamente, en la siguiente relación (figuras 15 y 16):

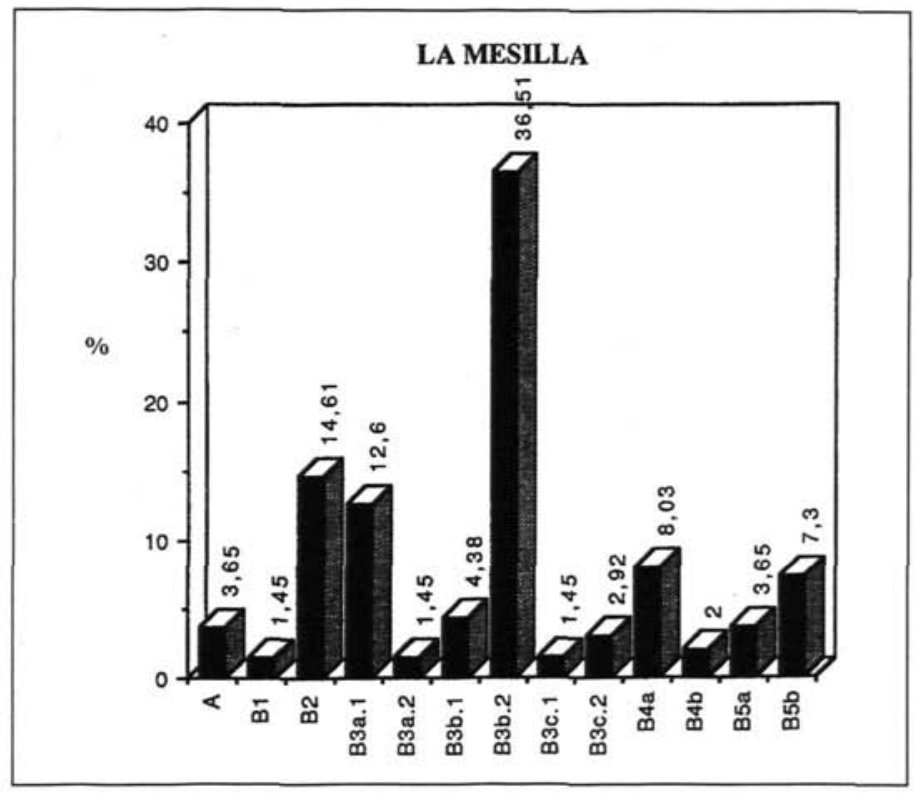

Figura 15. Comportamiento de las distintas variantes de bordes de la forma VI de La Mesilla.

- VIA: con cuello de tendencia vertical, prácticamente imposible de diferenciar del cuerpo, y borde igualmente vertical o muy ligeramente saliente, de unos $30 \mathrm{~cm}$. de diámetro. Esta variante, que parece estar directamente inspirada en grandes recipientes de almacén fabricados a mano, no resulta especialmente destacada ni en el conjunto ni en los demás yacimientos prerromanos bajoextremeños.

- VIB1: presentando ciertos paralelismos con la anterior, esta variante pertenecería a una vasija de almacén cerrada y de perfil globular cuya boca, de diámetro en torno a los 20 $\mathrm{cm}$., se marca con un pequeno cuello vertical de borde muy poco saliente, aunque ligeramente engrosado. Parece inspirarse, atendiendo a este último aspecto, en las ánforas iberopúnicas de borde grueso alzado, fechadas entre los siglos IV-II a.C. (PELLCER y OTROS, 
1983: 183), aunque con un resultado final muy matizado. Como sucede con la anterior, no es un perfil muy abundante, aunque está presente en otros yacimientos prerromanos extremeños como el de Belén (Rodríguez Díaz, 1991a: 49).

- VIB2: respondería al perfil de lo que se entiende como un "pithoi", con su cuello estrangulado y borde saliente más o menos apuntado, de diámetro oscilante entre los 35 y 60 $\mathrm{cm}$. Encontraríamos significativos paralelos no sólo en el ámbito prerromano bajoextremeǹo (RODríguez DiAz, 1991a: 55; BerRoCAL, 1992: 111), sino también en el turdetano (RuIz MATA, 1987: 305); una profusión de la que da muestra su relativa abundancia (14,61\% del total de las producciones torneadas) en La Mesilla, donde, además, puntualmente se constatan ejemplares decorados.

- VIB3a.1: se define como una gran urna, con el cuello estrangulado y cóncavo -y diámetro entre 20 y $50 \mathrm{~cm}$.-, que resulta bastante familiar en contextos meridionales andaluces (RUIZ MATA, 1987: 308), portugueses (BEIRẢo y otros, 1985: 77) y bajoextremeños (Rodriguez DiAz, 1987: 713, n² 25; 1991a: 49; BerRocal, 1994 a: 175). En el yacimiento que presentamos está bastante bien documentada (supone el 12,6\% de los vasos torneados), aunque excepcionalmente la encontramos decorada, y guarda no pocas similitudes con otra variante, la VIB3a.2, algo menos esbelta y menormente representada.

- VIB3b.1: es una variante de vasija de almacén, con cuello y borde en "S" de desarrollo corto aunque perceptible, con diámetros entre 23 y $60 \mathrm{~cm}$. Cuando la separación entre el cuello y el cuerpo viene marcada por una carena nos encontramos ante la variante VIB3b.2, que es, sin duda, la mejor representada de la forma VI $(36,51 \%)$. Resultaría seguramente interminable el listado de paralelos que ambas variantes presentan en los poblados prerromanos del Suroeste; pero restringiéndonos a aquellos enclaves cuyos vasos están mejor tipificados, destacariamos su presencia en la Ermita de Belén (forma IB) (Rodriguez Diaz, 1991a: 49), en Capote (tipo XIV) (Berrocal, 1992: 107; y 1994: 181), y en un buen número de yacimientos del Alto Alentejo Oriental, cuya referencia bibliográfica más destacable es, posiblemente, Cabeça de Vaiamonte (Morais y JúdicE Gamito, 1974-77: 175). En el amplio círculo que trazan estas menciones, los vasos -especialmente de la variante VIB3b.2- aparecen frecuentemente decorados con motivos estampillados, tal como se aprecia también en La Mesilla, constituyendo así un fósil muy definido entre los pueblos del Suroeste que, no obstante, se advierte en otros yacimientos extremeños del ámbito vettón, ya transicionales al mundo meseteño, como el de La Coraja (donde aparecen reconocidos como cerámica a mano tipo 2) (Esteban, 1993: 94).

- VIB3c.1: podría describirse como una variante caracterizada por un borde o cuello destacado y de tendencia vertical, a veces con una acanaladura o rehundimiento (que distingue a la variante VIB3c.2), con el labio apuntado al interior, y decoración estampillada sobre dicho cuello. Sus diámetros oscilan entre 28 y $40 \mathrm{~cm}$. Están, además, muy poco representadas en la muestra. Todo este conjunto de características nos obliga a emparentarlas especialmente con otros ejemplares -también muy poco abundantes- del yacimiento de Capote, donde definen las formas XVI-XVII (BERROCAL, 1994a: 185).

- VIB4a: se trata de una forma cuyo aspecto guarda no pocos paralelismos con el del tipo XIII de Capote (BERROCAL, 1994a: 177): sobre cuerpo globular, un cuello destacado e inclinado al exterior y con un borde apuntado. Sin embargo, la dimensión de los diámetros de estos vasos en La Mesilla -oscilante entre 35 y $50 \mathrm{~cm}$.- implica que no los concibamos como las urnas globulares de Capote (BERROCAL, 1992: 107), sino como verdaderas vasijas de almacén. La variante VIB 4 b, muy parecida a la anterior, se matiza con un leve escalón en el hombro, alli donde el cuello inicia su curva de inflexión, y un ligero engrosa- 


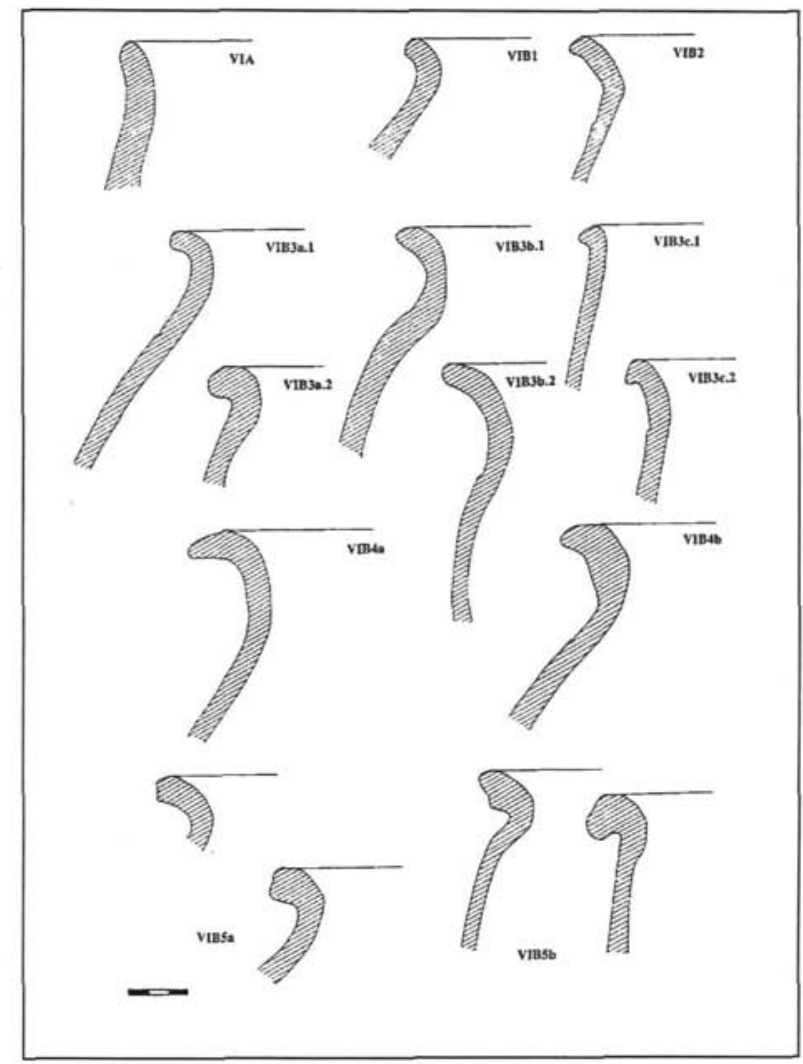

Figura 16. Cerámicas a torno toscas: variantes de la forma VI.

miento de este último. La primera variantes está relativamente bien representada en el seno de la forma VI $(8,03 \%)$, pero ambas ofrecen ejemplares decorados con estampillados. Al margen de su presencia en otros asentamientos bajoextremeños como el de la Alcazaba de Badajoz (EnRíquez y otros, 1998: 183), las destacaríamos en contextos del Alto Alentejo (MORAIS y JÚdicE GAMITO, 1974-77: 175) o la provincia de Cáceres (ESTEBAN, 1993: 94).

- VIB5a: acoge a una serie de bordes vueltos, exvasados, caracterizados por disponer de un labio ligeramente engrosado y dividido en dos por una hendidura. La intensificación de ambas propiedades permite la distinción de VIB5b, una variante algo más numerosa (hacia el 7,3\% de la forma VI), cuyos diámetros conocidos -entre 35 y $50 \mathrm{~cm}$.- nos inducen a incluirla entre las vasijas de almacén. Más que con horizontes estrictamente prerromanos, dichos perfiles podrían apuntarnos una ocupación del castro de La Mesilla hasta un momento avanzado, posiblemente en el horizonte republicano, a tenor de la documentación de perfiles muy similares en diversos yacimientos bajoextremenos, de los que el mejor conocido es el de Hornachuelos (Rodríguez DíaZ, 1987; Rodríguez y JiménEZ, 1987-88: 23: 1). 
- La Forma VII: acoge al grupo de vasijas de almacén de grandes proporciones, con diámetros entre 20 y $50 \mathrm{~cm}$., y paredes entrantes. Pueden considerarse perfiles directamente derivados de las ánforas iberopúnicas (PELLICER Y OTROS, 1983: 181185) (VIIA) o bien evolucionados hacia los recipientes tipo dolio (VIIB). Algunos ejemplares de esta última variante, que además está bastante bien representada en el conjunto de la muestra alangeña (suponiendo un $7,3 \%$ de las producciones torneadas), presentan decoraciones estampilladas, aplicaciones, etc. Los fragmentos de asas y aplicaciones de sujección presentes en el conjunto que estudiamos podrían pertenecer, muy posiblemente, a alguna de las variantes de esta forma (figura 17). Son perfiles bien conocidos en la región extremeña, como implica su documentación tanto en Belén (Rodríguez Díaz, 1991a: 49), la Alcazaba de Badajoz (Enríquez y otros, 1998: 183), Los Castillejos-2 (Rodríguez Díaz, 1987: 795) o Capote (Berrocal, 1994a: 185), como en La Coraja, donde se les ha considerado entre las cerámicas modeladas (ESTEBAN, 1993: 93).

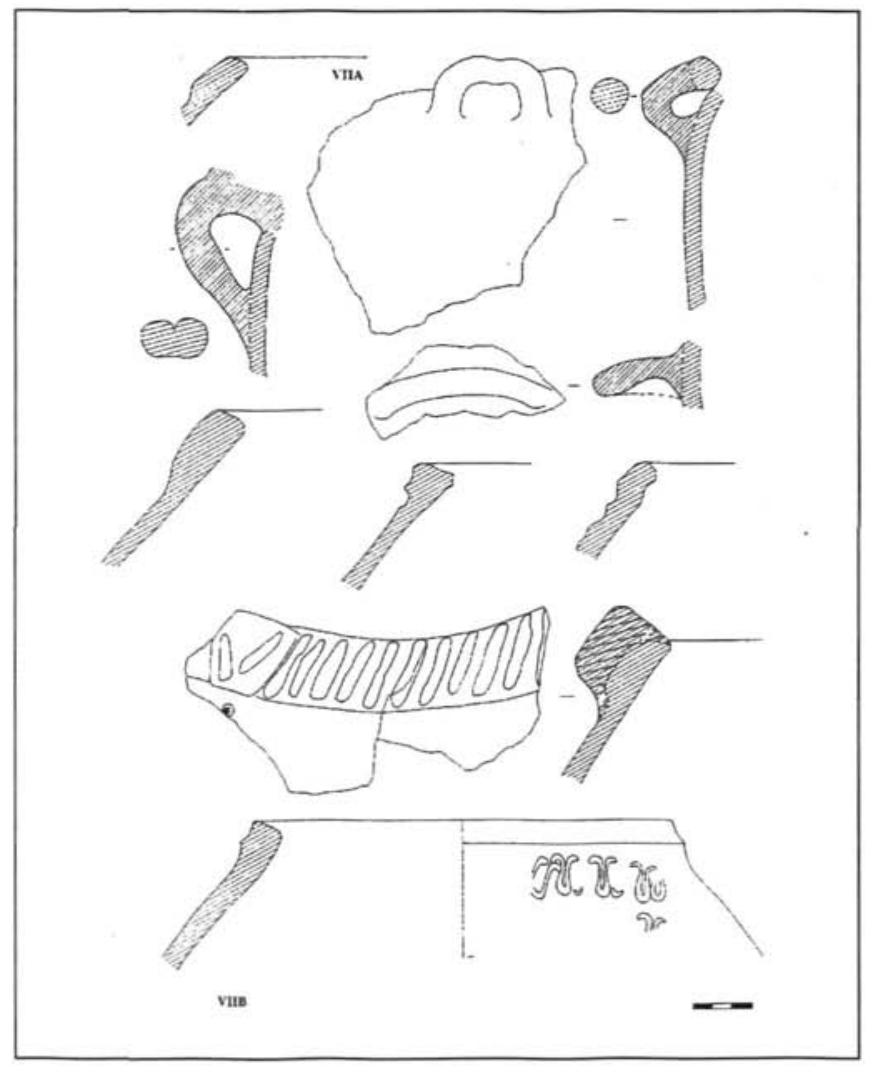

Figura 17. Cerámicas a torno toscas (VII). 


\subsection{B. Decoración}

En el extenso conjunto de las producciones a torno toscas, aquellas que presentan algún tipo de decoración suponen poco más del 7\%, según se ha indicado. Al margen de la valoración de esta cifra, en parte efectuada más arriba, debemos subrayar el notable grado de concreción a que conduce el estudio detenido de esta porción de la muestra. Así, cabe hablar, por una parte, de la importante presencia del estampillado como técnica ornamental, con una práctica que se impone estadísticamente (poco más del $91 \%$ de las cerámicas a torno toscas decoradas) a las demás, consistentes ya en la impresión de motivos circulares o rectangulares a punta de espátula, ya en la aplicación de cordones sobre los que se efectúa esa segunda decoración que en Capote se ha identificado como excisión (BERrocal, 1994a: 80 y 94). Por otra parte, cabe advertir de que todas estas decoraciones se aplican recurrentemente sobre las formas VI y VIIB de la tipología precedente, con lo cual resulta posible identificar las producciones vasculares toscas decoradas exclusivamente con algunos perfiles de vasijas de almacén.

Sin dejar de señalar las conexiones que los vasos estampillados apuntan con la Meseta, este conjunto, relativamente abundante en La Mesilla, de matrices impresas se inscribe más específicamente de una forma natural e inequívoca en el Tipo I de las cerámicas estampilladas bajoextremeñas (RODRíGuez DiAz, 1987: 780). Recordando las tendencias advertidas en otros poblados prerromanos, los motivos decorativos están realizados en negativo y se detectan en la parte superior del cuerpo de las vasijas, bien por debajo del cuello (en el caso de la forma VI), bien formando parte del mismo borde (en algunos ejemplares de la forma VIIB); siguiendo un esquema compositivo bastante regular, consistente en repetir una misma matriz en una banda horizontal, o bien una o dos matrices diferentes a lo largo de sendas bandas paralelas. Siguiendo estudios precedentes (ARNAUD y JúdICE GAMITO, 1974-77; BEIRÃo Y OTROS, 1985; Rodríguez Díaz, 1987 y 1991a; Berrocal, 1992 y 1994), podemos hablar de un abanico bastante amplio de matrices, susceptible de dividirse en nueve apartados (Figuras 18 y 19):

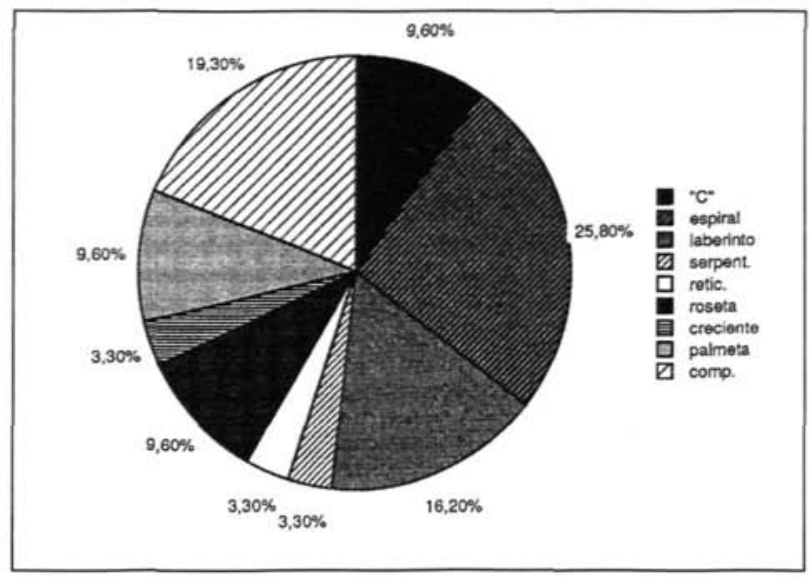

Figura 18. Matrices estampilladas en cerámicas toscas de La Mesilla. 
- 1ㅜ: motivos en "C" (figura 19, 1), que recuerdan a los documentados en la Ermita de Belén como bastoncitos, donde, sin embargo, aparecen sobre productos modelados (Rodríguez Diaz, 1991a: 52, $\mathrm{n}^{2}$ 4). También en el Altar prerromano de Capote se documentan matrices -incluidas por su excavador en el apartado de "varios"que se inspiran en el mismo concepto (BERROCAL, 1994 a: $112, \mathrm{n}^{2} 140$ y 1406). No es un motivo extraño en tierras del Alto Guadalquivir (RuIz y NOCETE, 1981: 361, $\mathrm{n}^{\circ}$ 27). En La Mesilla aparecen siempre sobre perfiles de la forma VI.

- $2^{\text {o: }}$ : motivos en espiral o círculos concéntricos (figura 19, 2), que son los mejor representados en la muestra alangeña, donde se dan sobre vasos similares a los de la matriz anterior. Respirando el mismo aire que alguna documentada en Capote (BerRoCAL, 1994a: 109, n² 2542) o la fase I de los Castillejos-2 de Fuente de Cantos (Rodriguez Diaz, 1987: 795, n² 5; o 1989: 196), se pueden establecer relaciones con otras estampillas altoalentejanas (ARNAUD Y JúdiCE GaMito, 1974-77: 167, $\mathrm{n}^{2} 70$; BEIRÃo y otros, 1985: 75, n² 4), o cacereñas (Esteban, 1993: 94, c).

- 3ㅜ: motivos en laberinto (figura 19, 3 y 4), ocupando el tercer lugar en orden de importancia cuantitativa, no constituyen una matriz especialmente destacada hasta el momento en la Baja Extremadura (Rodríguez Díaz, 1987: 777-798). Las mejores referencias las encontramos en Capote (BERROCAL, 1994a: 111, $\mathrm{n}^{2} 1182$ y 3300), donde, a diferencia de los casos de La Mesilla, aparecen sobre un fondo rectangular. Con la misma idea, aunque con resolución distinta, podemos señalar algunos motivos altoalentejanos (ARNAUd Y JÚdiCE GAMITO, 1974-77: 166, $\mathrm{n}^{2} 85$ ) y, especialmente, del Alto Guadalquivir (Ruz y NOCETE, 1981: 359, $\mathrm{n}^{2} 11-20$; y 360, $\mathrm{n}^{2} 1-19$ ). Los casos de La Mesilla aparecen, una vez más, sobre la forma VI.

- $4^{\circ}$ : motivos serpentiformes (figura 19,5 ), que resultan muy poco abundantes en esta muestra, limitados a una presencia sobre la forma VIIB, aunque bien conocidos como motivos en "S" sobre vasos a mano en Belén (Rodríguez DiAz, 1991 a: 52, $\mathrm{n}^{2}$ 1), en Capote (BerRoCAL, 1994a: 112, $\mathrm{n}^{2} 5111$ ), en Vaiamonte (ARNAUd y JúdicE GAMITO, 1974-77: 168, n² 7) o en La Coraja (Esteban, 1993: 94, b)

- 5': motivos reticulados en enmarque cuadrangular (figura 19, 6), poco abundantes en La Mesilla, aunque bien conocidos en ambientes bajoextremeños: la Ermita de Belén (Rodríguez Diaz, 1991a: 52, n² 8), la fase I de los Castillejos-2 (Rodríguez Díaz, 1987: 795), Capote (Berrocal, 1994 a: 111, $\mathrm{n}^{2} 3299$ ), etc. En la provincia de Cáceres tampoco resultan extraños (CABELLO, 1991-2: 123).

- 6: motivos en roseta (figura 19, 7), con diferente número de radios/pétalos, bien representados tanto en la muestra como en otros yacimientos del Suroeste, de los que buena prueba son los españoles de Belén (Rodríguez Díaz, 1991a: 52, n² 14), Capote (Berrocal, 1994a: 109, $\mathrm{n}^{2} 5110$, etc.), los Castillejos-2, Sierra de la Oliva, Las Poyatas, Hornachuelos (Rodríguez Diaz, 1987: 795 y 797), La Tabla de las Cañas de Capilla (Domínguez y Garcia, 1991: 242), la Alcazaba de Badajoz (Enríquez y otros, 1998: 183), etc.; o los portugueses de Vaiamonte (ARNAUd Y Júdice Gamito, 1974-77: 166, $n^{2} 79$ ), Garvão (Beirảo y otros, 1985: $75, n^{2} 3$ ), etc. Fuera de este ámbito, en 
las zonas limítrofes, encontramos estas matrices tanto en la Alta Andalucía (Ruz Y NOCETE, 1981: 360 y 361) como en tierras cacereñas (CABELLO, 1991-2: 123 y 127; Esteban, 1993: 94, a).

- $7^{\circ}$ : motivos en media luna (figura 19,8 ), marginalmente representados en esta muestra y raros en el ámbito bajoextremeño, donde tal vez estén inspirados en representaciones similares a crecientes conseguidos mediante la impresión de punzadas sobre cerámicas modeladas (BERROCAL, 1994 a: 98, n² 1397).

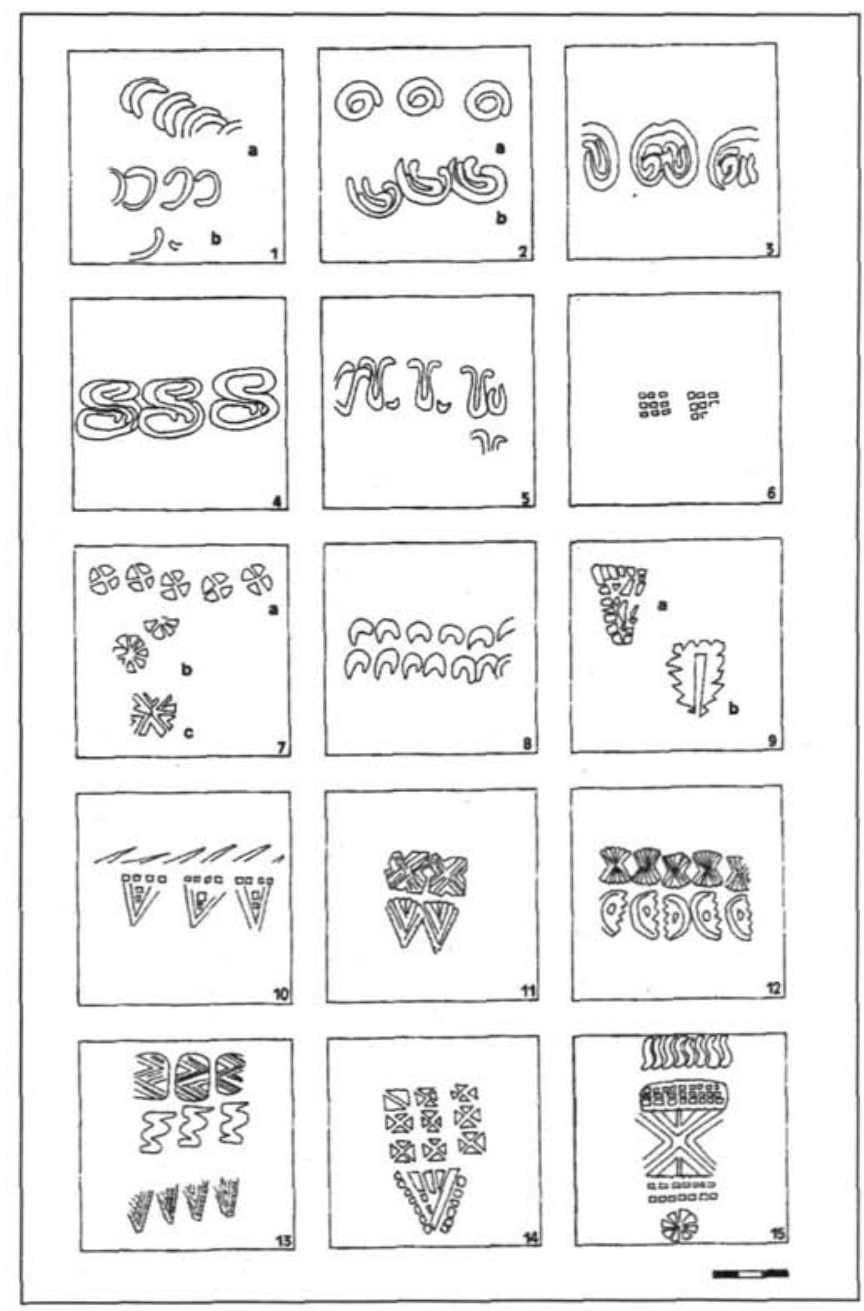

Figura 19. Motivos estampillados en cerámicas toscas de La Mesilla. 
- $\mathbf{8}^{\text {o: }}$ : motivos en escudete-palmeta (figura 19, 9), aplicados sobre vasos de las formas VI y VIIB, similares a los ya conocidos de Belén (Rodríguez Díaz, 1991a: 52, n²9), Capote (BERROCAL, 1994a: 111, n² 240 y 532), los Castillejos-2, y demás yacimientos bajoextremeños (Rodríguez DiAz, 1987: 795 y 797) o altoalentejanos (ARNAUD Y JÚDICE GAMITO, 1974-77: 166; BEIRẢO, 1985: 75).

- 9\%: motivos compuestos (figura 19,10 a 15), es decir, composiciones ornamentales algo más complejas, en cuyas bandas se dan cita más de dos estampillas, como los documentados sobre diversos fragmentos de las formas VI y VIIB. Así, conocemos la combinación de reticulados de polígonos radiados y escudetes; aspas y escudetes; estilizaciones en "S" o "Z" encadenadas, reticulados, polígonos radiados y rosetas, etc.; motivos todos ellos que, independientemente, resultan muy conocidos en el ámbito suroccidental durante la Segunda Edad del Hierro, como ha podido comprobarse.

Pero, centrándonos más concretamente en la geografia bajoextremeña, hemos de recordar que algunos conjuntos de estampillas del mismo tipo que las que ahora presentamos han sido recuperados en contextos estratigráficos bien definidos, circunstancia que supone una gran ayuda a la hora de intentar afinar aún más la adscripción de los materiales alangeños. En este sentido, una de las primeras referencias en valorarse fue la documenta-

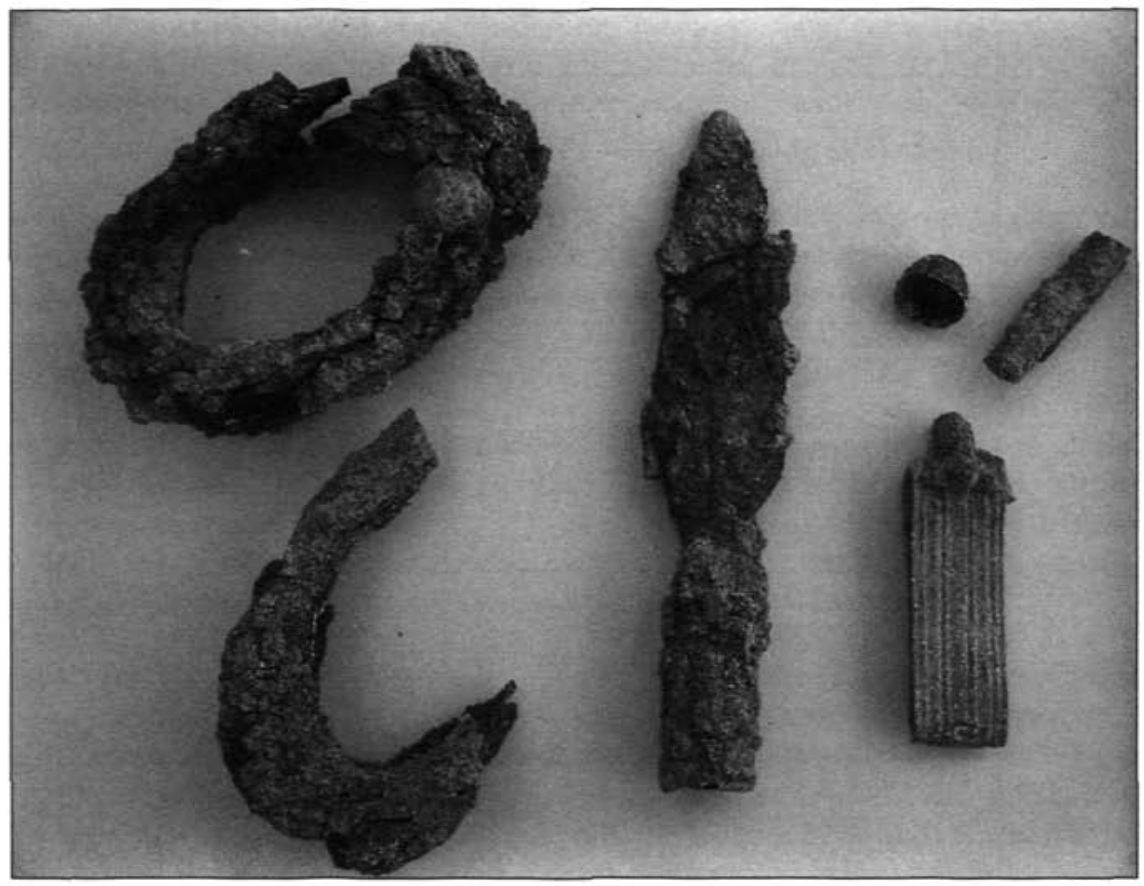

Figura 20. Objetos metálicos recuperados en La Mesilla. 
ción de matrices similares asociadas esencialmente a la fase I del poblado de los Castillejos2 de Fuente de Cantos (Rodríguez Díaz, 1987: 785), fechada hacia los siglos IV-III a.C., y ubicada inicialmente en el Horizonte Cultural Túrdulo-turdetano (FERNÁNDEZ y otros, 1988: 82), aunque hoy considerado más bien Céltico (Rodríguez Díaz, 1995b: 97). En un ambiente calificable también como céltico, encontramos obligadas referencias en Belén, Capote y la Alcazaba de Badajoz. En el primero de estos yacimientos, la mejor referencia procede del Corte 1, donde las estampillas, presentes en todos los niveles, resultan especialmente representativas de las fases I y II, entre el siglo IV y los comienzos del II a.C. (Rodríguez Diaz, 1991a: 69-71). En Capote, las matrices del Depósito A -similares a las de La Mesilla- se vienen situando entre comienzos o mediados del siglo IV y mediados del siglo II a.C. (BERrocal, 1992: 100; 1994: 261). En la Alcazaba de Badajoz parece evidente que el advenimiento de la ornamentación estampillada se sitúa también en el Hierro II Pleno, de entre el siglo IV y mediados del II a.C. (Berrocal, 1994b: 175; ENríquez y otros, 1998: 184). Fuera de este ámbito cultural, debemos señalar la escasez de excavaciones realizadas en el sector de la Beturia Túrdula, donde destaca casi exclusivamente la presencia de estampillas desde la fase I -hacia los siglos IV-III a.C.- de la Tabla de las Cañas (Capilla) (DomíngueZ y GARCíA, 1991: 242).

Al margen de las producciones cerámicas, del yacimiento proceden algunos objetos metálicos mal conservados - una punta de lanza de hierro entre ellos- que, a falta de un proceso de limpieza que permita un examen más detenido, poco aportan al panorama cultural esbozado a partir del estudio de los vasos (figura 20).

\section{CONCLUSIONES}

En función de los datos recogidos, estamos en condiciones de abordar una caracterización preliminar de la ocupación protohistórica de La Mesilla, siendo conscientes tanto de la naturaleza limitada del registro, especialmente por el volumen de material y su procedencia accidental, como de la necesidad de una excavación arqueológica que permita afinar cuanto aquí se expone. Dicha valoración pasa, una vez realizado el análisis precedente, por una tarea de síntesis que inexcusablemente debe contemplar la contextualización de estos datos en la realidad prerromana bajoextremeña.

El patrón de asentamiento y las características del yacimiento de La Mesilla lo acercan a ese grupo de pequeños poblados prerromanos, de hasta 3 hectáreas de extensión, que la investigación ha venido advirtiendo en el contexto global bajoextremeño (RoDríGUEz DiAz, 1989: 173-4; Berrocal, 1992: 275). Presentes en la Beturia Túrdula, donde el caso más paradigmático es, posiblemente, la Tabla de las Cañas (Domínguez y GARCí, 1991), los yacimientos de estas características mejor conocidos se ubican en la Céltica, caso de los Castillejos-2 de Fuente de Cantos (Fernández y otros, 1988), la Martela de Segura de León (Enríquez y Rodríguez, 1988), la Ermita de Belén de Zafra (Rodríguez Díaz, 1991a) y Capote en Higuera la Real (BERroCAL, 1992 y 1994a). En conjunto se han señalado para ilustrar lo que se entiende como un "castro" prerromano: un poblado fortificado de dimensiones más bien reducidas, aspecto encastillado, discreta altitud y tendencia a no destacar topográficamente del entorno; condiciones todas ellas que, en mayor o menor medida, parecen reproducirse también en La Mesilla. Respecto a la reconstrucción semimicro y microespacial, ninguna novedad puede 
desprenderse de la información hasta el momento aportada por este yacimiento. Independientemente de todo lo anterior, una circunstancia de no menos interés la constituye el hecho de que las estratigrafias de todos estos enclaves, por lo que sabemos hasta hoy, comiencen a partir del siglo IV a.C., definiendo una nueva estrategia de ocupación del espacio, claramente rupturista -pese a lo defendido no hace mucho por otros investigadores (BerRoCal, 1995: 172-173) - con el poblamiento del Bronce Final-Orientalizante, basada en este nuevo tipo de asentamientos (Rodríguez Diaz, 1995c: 169).

Puesto que hoy en día resulta posible acercarse, con un cierto margen, a la definición de las fases de ocupación de los poblados prerromanos merced al buen conocimiento alcanzado principalmente sobre los materiales cerámicos, del recorrido efectuado por el muestreo de La Mesilla pueden extraerse una serie de impresiones acerca de su eventual inclusión en ese conjunto de los castros bajoextremeños. Así, del análisis precedente se deduce que la primera ocupación del sitio parece tener lugar, efectivamente, en época prerromana. Ningún perfil, ni decoración, de los vasos recuperados es susceptible de interpretarse en otro sentido. Todas las familias documentadas, las formas y las decoraciones nos remiten a ese mismo horizonte prerromano y a ese segmento cronológico trazado entre los siglos IV-II a.C. Cerámicas a mano, grises, oxidantes y toscas definen un universo material rastrable a grandes rasgos, como hemos visto, en un buen número de yacimientos bajoextremeños del Hierro II. Más allá de ello, y sin pretender una aproximación étnica que trascienda lo meramente material, los trazos tecnológicos, morfológicos y ornamentales acercan más las producciones de La Mesilla a las del círculo etnocultural céltico (Rodríguez Díaz, 1991a; Berrocal, 1992) que a las del túrdulo-turdetano (Rodríguez Diaz, 1994: 23; 1995a: 228-9), a pesar de su ubicación al este de la futura "Vía de la Plata" (BERrocal, 1995: 159), posiblemente por su situación en el límite de ambos territorios y la cercanía al curso del Guadiana, que estimamos determinante. Desde estas impresiones, las expectativas generadas en torno a la aparición de un nuevo yacimiento que pudiera contribuir a definir mejor la naturaleza de la ocupación prerromana del Valle del Matachel en la Beturia Túrdula, plasmadas al comienzo de este trabajo, efectivamente hay que reconducirlas hacia el reconocimiento de que dicho espacio constituye un área individualizada y, a la vez, diversa (Rodríguez Díaz, 1995a: 209), donde, como ya se ha dicho, tal vez sean precisamente esos ingredientes alentejano-meseteños (apreciados en muy diversa proporción, eso sí, en La Mesilla, la Tabla de las Cañas, El Cerro del Castillo de Bienvenida, etc.) los que mejor ayuden a advertir el hecho diferencial de "lo túrdulo" respecto a "lo turdetano" (Rodríguez Díaz: 1995a: 214, 221, 230), entendiendo la esencia de lo primero -y complementando en cierto modo la versión de Polibio- en el mestizaje, sobre un sustrato orientalizante diluido, de elementos continentales, turdetanos e incluso neopúnicos (OrTIZ y RodríguEz, 1998: 256).

Al margen de que el estado actual de la investigación impida ir más allá en la valoración de los materiales alangeños, no queremos dejar de hacer explícitamente una llamada de atención sobre la necesidad apremiante de caracterizar y acotar mucho mejor el horizonte estrictamente prerromano de la Beturia Túrdula, toda vez que en no pocos casos resulta complicado aislarlo del republicano (RodríGuez Díaz, 1987), siendo incluso en algún otro, como de hecho sucede con la fase IV de Medellín, hasta difícil de aceptar, en base a la indefinición o ausencia de fósiles directores más o menos claros (AlMAGro y MARTiN, 1994: 115). La reso- 
lución de este problema, por otra parte, sólo podrá acometerse desde un estudio estratigráfico riguroso que complemente los de las escasas excavaciones hasta hoy desarrolladas.

En el conjunto de materiales recuperados en La Mesilla, por otra parte, no hay indicios que permitan suponer una romanización de este enclave en el sentido de una supervivencia del mismo hasta época imperial, sino tan sólo un contacto con la fase republicana similar al advertido en otros castros (Rodríguez Díaz, 1994: 25; 1995b: 106-7). Algo se ha escrito ya sobre el interés de los corredores naturales de La Serena y del Matachel en el momento de las luchas sertorianas y la actuación de César (Rodríguez Díaz, 1995a: 231; Ortiz Romero, 1995: 190), y sin duda más se escribirá en los próximos años, pero por el momento dichas líneas ayudan a entender, mediante "una política territorial y de relocalización de elementos indígenas dirigidas a su sometimiento militar, su explotación económica y su reconducción sociopolítica e ideológica", no sólo el surgimiento de recintos, fortificaciones y oppida, sino también un ocaso del mundo de los castros (Rodríguez Díaz, 1995c: 170), en el que hay que contextualizar la aparente extinción del poblado de La Mesilla. Cierto es que en el casco urbano y término de Alange hay constancia de restos arqueológicos y arquitectónicos varios fechados a lo largo de la época imperial romana (ÁlLAREz, 1973; RoDríguez Díaz, 1986: 115186; CAlero y Márquez, 1991: 585-590; Gimeno, 1997), pero estimamos que el origen de todos ellos obedece a procesos que difícilmente tienen que ver con una continuidad del castro de raíces indígenas como unidad habitacional, y mucho más con la dinámica impuesta por un concepto territorial novedoso, como es la ciudad, plasmado en la fundación de Augusta Emerita (ENRÍQUEZ, 1997: 42).

Pero el interés tal vez mayor que, de cara al debate historiográfico actual, posee el yacimiento que ahora estudiamos, radica seguramente en sus posibilidades interpretativas con vistas al estudio de los patrones de asentamiento y, en general, a la estructura y dinámica del poblamiento en la protohistoria de la zona. En este sentido, y según lo que hasta hoy sabemos, la traslación del hábitat desde el Cerro del Castillo a La Mesilla supone el abandono, tal vez sólo parcial, de un espacio ocupado desde la Edad del Bronce y -presumiblemente- el período Orientalizante, y la creación de otro nuevo, bajo premisas también inéditas, a escasa distancia y menor altitud que el anterior, como hemos referido más arriba. Tras ese episodio, los materiales recogidos en superficie permiten defender una reocupación del Cerro del Castillo en momentos avanzados de la República (Rodríguez Díaz, 1995a: 251).

Aunque en otro contexto geográfico, como es el de la Penillanura Cacereña -y atendiendo a parámetros también diferentes-, no deja de llamarnos la atención la similitud de comportamientos, en cuanto a dinámica ocupacional, entre el caso alangeño que nos ocupa y el que, con un fundamento crono-estratigráfico más aquilatado, hemos dado a conocer recientemente a propósito del poblado protohistórico de la Sierra del Aljibe en Aliseda (Cáceres) (PAVÓN Y OTROS, 1998: 131; PAVón y Rodríguez, e.p.). Allí, la secuencia estratigráfica ha permitido documentar, tras una ocupación ininterrumpida que abarca desde el Bronce Final avanzado hasta el período Orientalizante Tardío (Aliseda I, II y III), un abandono del lugar durante el Hierro II y una posterior reocupación Tardo-republicana (Aliseda IV). Además, coincidiendo con el mencionado vacío en el poblado en alto de la Sierra del Aljibe durante el Hierro II es posible advertir en la misma zona y a no mucha distancia la proliferación de otros yacimientos que, como el de Sansueña, ofrecen a un patrón de asentamiento 
radicalmente distinto, topográficamente menos destacado, respondiendo a lo que se conoce como un "castro de ribero". Pero independientemente de estas cuestiones -existiendo o no equivalencia con lo sucedido en tierras cacereñas-, y volviendo al caso alangeño, posiblemente haya que interpretar dicha traslación desde el Cerro del Castillo a La Mesilla desde ciertas claves rupturistas, en consonancia con la nueva situación que más específicamente supone el Hierro II en la "Cuenca Media del Guadiana", la "continentalización" y la reconducción económica que en el mediodía sigue al final de Tartessos (Rodríguez Díaz, 1994: 20), aunque matizadas, sin duda, por su contextualización en lo que es estrictamente "Valle Medio del Guadiana".

\begin{tabular}{|l|c|l|c|l|c|}
\hline MANO & Abs. & BASES MANO & Abs. & TOSCAS & Abs \\
\hline IA & 44 & A1 & 3 & I & 2 \\
IB1 & 12 & A2 & 12 & II & 4 \\
IB2 & 4 & B1 & 9 & III & 7 \\
II.p & 13 & B2 & 2 & IV & 2 \\
II.m & 13 & GRISES & Abs. & V & 1 \\
III.p & 4 & I & 1 & VIA & 5 \\
III.m & 10 & IIA & 4 & VIB1 & 2 \\
IVA.p & 3 & IIB & 1 & VIB2 & 20 \\
IVA.m & 2 & III & 2 & VIB3a.1 & 17 \\
IVB.p & 3 & OXIDANTES & Abs. & VIB3a.2 & 2 \\
IVB.m & 7 & I & 1 & VIB3b.1 & 6 \\
V & 2 & IIA & 35 & VIB3b.2 & 50 \\
VI & 22 & IIB & 1 & VIB3c.1 & 2 \\
VIIA & 2 & IIC & 1 & VIB3c.2 & 4 \\
VIIB & 15 & IIIA & 2 & VIB4a & 11 \\
VIIC & 1 & IIIB & 1 & VIB4b & 3 \\
VIIIA & 1 & IVA & 6 & VIB5a & 5 \\
VIIIB & 3 & IVB & 6 & VIB5b & 10 \\
IXA & 3 & IVC & 4 & VIIA & 1 \\
IXB & 1 & IVD & 3 & VIIB & 6 \\
Fusayolas & 2 & V & 1 & Otras & 84 \\
\hline
\end{tabular}

Figura 21. Registro absoluto de la industria cerámica en La Mesilla. 
Cierto es que hasta hoy se ha venido defendiendo una continuidad poblacional de determinados enclaves del Valle del Guadiana (Medellín, Cerro del Castillo de Alange y Alcazaba de Badajoz, principalmente) que conforman una "facies de poblados de vado ", con raíces en distintos momentos del Bronce (PAvón, 1995) y ocupación casi ininterrumpida hasta la Edad Media... y dado que eso, a grandes rasgos, parece así (RodríguEz Díaz, 1995c: 1679), tal vez haya que llamar la atención, indirectamente, sobre el comportamiento diferencial que ante la "crisis del 400" (RODRíGuez DíAz, 1994) parecen experimentar las distintas tierras bajoextremeñas. Mientras en el conjunto de la "Cuenca" dicha coyuntura supone realmente una fracción en el poblamiento (Rodríguez DíAz, 1995c: 168, gráfico 1), dentro del "Valle" resulta posible advertir ese proceso de falla diferenciando el comportamiento, aparentemente homogéneo en el declive, de las denominadas "arquitecturas de prestigio" (RoDríguEz Y Ortiz, 1998: 238), del de los "poblados de vado", donde sin embargo, e incipientemente, la investigación ya comienza a advertir distintas reacciones que tal vez haya que revisar, y entender, desde su individualidad.

En Alange, recapitulando, los materiales recogidos en ese referente macroespacial de primer orden que es el Cerro del Castillo, a la luz de su contraste con los de La Mesilla, abogan más bien, según acabamos de decir, por una cronología republicana y, consecuentemente, una reocupación del hábitat tradicional en dichos momentos avanzados. Alternativamente, la aparición de La Mesilla poco después de inaugurado el siglo IV a.C. supondría una simple relocalización -en cierto modo mimética al surgimiento de los otros castros de la Beturia- a escasa distancia del anterior, sin perder de vista los seculares objetivos geoestratégicos (control visual de los vados del Guadiana desde una cierta distancia, del tramo bajo del Matachel, de las tierras...), pero ofreciendo, tal vez, una cierta orientación al control de los limitados recursos férricos de la comarca-de los pocos que se encuentran en Extremadura fuera de la Reserva de Hierros del Suroeste y de la Cuenca del río Ibor-situados precisamente en la prolongación oriental de la serreta donde se ubica (Florido, 1987: mapa previsor de mineralizaciones anexo). Por su parte, en la Alcazaba de Badajoz recientemente hemos llamado la atención sobre la necesidad de no considerar los indicios de "continuidad" y "ruptura" en patrón de asentamiento y estratigrafía como realidades totalmente excluyentes, por lo que no estimamos necesario volver sobre ello (ENRiQuez y OTROs, 1998: 196). Y en Medellín, finalmente, quizá sea hora de reflexionar no sólo sobre la verdadera naturaleza de las fases IV y V del poblado (Almagro y MARTín, 1994: 114-6), como más arriba hemos apuntado, sino también sobre la fechación a finales del siglo V a.C. de los estratos cenicientos asociados a la fase III-C, que siembran sobre sus excavadores una duda razonable acerca de un incendio en el poblado, tal y como ya ha recordado Rodriguez Diaz (1994: 15). Es más, la propia conclusión de la necrópolis en torno al 400 y su no utilización durante el horizonte prerromano de Medellín IV viene a redundar en los tintes diluidamente rupturistas que, también en este "poblado de vado" del Valle Medio del Guadiana, va resultando posible intuir. En suma, son esbozos que tal vez pudieran ocultar claves importantes para perfilar la verdadera naturaleza de esa realidad protohistórica tan atractiva como diversa, y aún tan susceptible de matizaciones a causa de su complejidad, que es la Beturia. 


\section{BIBLIOGRAFÍA}

Almagro Gorbea, M. y Martín Bravo, A.M. (1994): "Medellín 1991. La Ladera Norte del Cerro del Castillo". Castros y Oppida en Extremadura (Edes. Almagro Gorbea, M. y Martín, A.M.). Complutum Extra, 4. 77-127.

Álvarez Martinez, J.M. (1973): “Alange y sus termas romanas". Revista de Estudios Extremeños, XXIX, III. 445-494.

Beiräo, G. De Mello, Tavares da Silva, C., Soares, J., Varela Gomes, M. Y Varela Gomes, R. (1985): "Depósito votivo da II Idade do Ferro de Garvão. Notícia da primeira campanha de escavaçoes”. O Arqueólogo Portugués, Serie IV, Vol. III. 45-136.

- (1985-86): "Um depósito votivo da II Idade do Ferro, no sul de Portugal, e as suas relaçoes com as culturas da Meseta". Veleia, 2-3. 207-221.

Bflén Defamos, M. (1976): "Estudio y tipología de la cerámica gris en la Provincia de Huelva". Revista de Archivos, Bibliotecas y Museos, LXXIL, 2. 353-388.

Belén, M. Y Pereira, J. (1985): "Cerámicas a torno con decoración pintada en Andalucía". Huelva Arqueológica, VII. 307-360.

Berrocal Rangel, L. (1992): Los Pueblos Célticos del suroeste de la Península Ibérica. Complutum Extra, 2.

- (1994a): El altar prerromano de Capote. Ensayo etno-arqueológico de un ritual céltico en el suroeste peninsular.

- (1994b): "El Oppidum de Badajoz. Ocupaciones prehistóricas en la Alcazaba". Castros y Oppida en Extremadura (Ed. Almagro Gorbea, M. y Martín, A.M.). Complutum Extra, 4. 143-187.

- (1995): "La Beturia: definición y caracterización de un territorio prerromano". Celtas y Türdulos: la Beturia. Cuadernos Emeritenses, 9. 151-204.

- (1996): "Fortificación, guerra y poblamiento en la Beturia: consideraciones sobre el altar de capote y la conquista del Suroeste”. Revista de Estudios Extremeños, LII-2. 411-440.

CABEllo CAJA, R. (1991-92): "La cerámica pintada de la II Edad del Hierro en la Cuenca Media del Tajo". Norba, 11-12. 99-128.

Calero Carretero, J.A. Y Márquez Gabardino, A. (1991): "Prospecciones, sondeos y excavaciones en Alange (1984-1987)". I Jornadas de Prebistoria y Arqueología en Extremadura (1986-1990). Extremadura Arqueológica, II. 579-597.

CARO BELLIDO, A. (1989): Cerámica gris a torno tartesia.

Coflho Ferreira Da Silva, A. y Varela Gomes, M. (1992): Protobistoria de Portugal.

Dominguez De La Concha, M.C. y García Blanco, J. (1991): "La Tabla de las Cañas (Capilla, Badajoz). Apuntes preliminares". I Jornadas de Prebistoria y Arqueologia en Extremadura (1986-1990). Extremadura Arqueológica, II. 235-245.

Enriquez Navascués, J.J. (1997): "La Mérida prerromana y el poblamiento pre y protohistórico de su comarca". Mérida ciudad y patrimonio, 1. 29-43. 
EnRíuez, J.J. y JimÉnez, E. (1989): Las tierras de Mérida antes de los romanos (Prehistoria de la comarca de Mérida).

Enríquez, J.J. y Rodríguez, A. (1988): "Campaña de Urgencia en la Sierra de La Martela (Segura de León, Badajoz)”. Extremadura Arqueológica, I. 113-128.

Enríquez, J.J., Valdés, F., PAVón, I., Rodriguez, A. y LóPEZ, P. (1998): "La estratigrafía del Sector Puerta de Carros-2 (SPC-2) de Badajoz y el contexto poblacional del Valle Medio del Guadiana en la Edad del Hierro". Extremadura Protohistórica: Paleoambiente, Economía y Poblamiento (Coord. Rodríguez Díaz, A.). 157-199.

Escacena Carrasco, J.L. (1979-80): "La cerámica ibérica de la Mesa de Setefilla (Sevilla)". Pyrenae, 15-16. 181-210.

- (1987): "El poblamiento Ibérico en el Bajo Guadalquivir". Iberos. Actas de las I Jornadas sobre el mundo ibérico. Jaén, 1985. 273-297.

Esteban ORTEGA, J. (1993): "El poblado y la necrópolis de La Coraja, Aldeacentenera, Cáceres". El Proceso Histórico de la Lusitania Oriental en época prerromana y romana. Cuadernos Emeritenses, 7. 55-112.

FernándeZ, J.M., SAUCEdA, M.I. y Rodríguez, A. (1988): "Los poblados calcolítico y prerromano de Los Castillejos (Fuente de Cantos, Badajoz)”. Extremadura Arqueológica, I. 6988.

Florido LARAÑa, P. (Dir.) (1987): La mineria en Extremadura.

García Iglesias, L. (1971): "La Beturia, un problema geográfico de la Hispania Antigua". Archivo Español de Arqueologia, 44. 86-108.

García y Bellido, A. (1945): España y los españoles hace dos mil años, según la "Geografia" de Strabón.

- (1947): La España del siglo I de nuestra Era (según P. Mela y C. Plinio).

Gimeno Pascual, H. (1997): "El peñasco de Alange (Badajoz) (CIL II 1024)". Revista de Estudios Extremeños, LIII.

Hernández Carretero, A.M. (1996): Estudio de las relaciones culturales durante la II Edad del Hierro en la Cuenca Media del Guadiana: La cerámica gris.

Hernández, F., Rodríguez, M.D. y Sánchez, M.A. (1989): Excavaciones en el castro de Villasviejas del Tamuja (Botija, Cáceres).

Júdice Gamito, T. (1981): “A propósito do castro de Segóvia (Elvas). Resistência a Roma no Sudoeste peninsular”. Historia, 29.

- (1983): "A Idade do Ferro no sul de Portugal. Problemas e perspectivas". Revista Arqueología, 6. 3-16.

- (1992): "Paleoetnología do Centro e Sul de Portugal". Paleoetnología de la P. Ibérica. Complutum 2-3. 329-337.

MONSAlud, M. de (1901): “Citanias extremeñas”. Revista de Extremadura, III. 6-13. 
Morais ARnaUd, J. Y Júdice Gamito, T. (1974-77): "Cerámicas estampilhadas da Idade do Ferro do sul de Portugal. I - Cabeça de Viamonte-Monforte”. O Arqueólogo Portugués, Serie III, Vol. VII-IX. 165-202.

Ortiz Romero, P. (1995): "De recintos, torres y fortines: usos (y abusos)". Homenaje a la Dra. $D^{\underline{a}}$ Milagro Gil-Mascarell Boscà. Extremadura Arqueológica, V. 177-193.

Ortiz Romero, P. Y Rodríguez Díaz, A. (1998): "Culturas indígenas y romanización en Extremadura: castros, oppida y recintos ciclópeos". Extremadura Protohistórica: Paleoambiente, Economia y Poblamiento (Coord. Rodríguez Díaz, A.). 247-278.

Pavón Soldevila, I. (1995): El tránsito del II al I milenio a.C. en las cuencas medias de los ríos Tajo y Guadiana: la Edad del Bronce. Tesis Doctoral inédita. Universidad de Extremadura (estando en prensa el presente artículo, este trabajo fue editado por el Servivio de Publicaciones de la Universidad de Extremadura, Cáceres, con fecha de 1998).

PAvón Soldevila, I. y Rodriguez Díaz, A. (e.p.): "Excavaciones de urgencia en el poblado protohistórico de Aliseda (Cáceres). Avance preliminar". II Congreso de Arqueología Peninsular (Zamora, del 24 al 27 de septiembre de 1996).

Pavón, I., Rodriguez, A. y Enríquez, J.J. (1998): "El poblamiento protohistórico en el Tajo Medio: excavaciones de urgencia en El Risco y Aliseda (Cáceres)". Extremadura Protohistórica: Paleoambiente, Economía y Poblamiento (Coord. Rodríguez Diaz, A.). 121-156.

Pellicer, M., Escacena, J.L. y Bendala, M. (1983): El Cerro Macareno. Excavaciones Arqueológicas en España, 124.

Pereira Sifso, J. (1988): "La cerámica ibérica de la Cuenca del Guadalquivir. I. Propuesta de clasificación". Trabajos de Prebistoria, 45. 143-173.

- (1989): "La cerámica ibérica de la Cuenca del Guadalquivir. II. Conclusiones". Trabajos de Prebistoria, 46. 149-159.

Ronkigufz Diaz, A. (1986): Arqueología de Tierra de Barros.

- (1987): El poblamiento prerromano en la Baja Extremadura. Tesis Doctoral (Edición microfichada, Cáceres, 1996).

- (1989): "La Segunda Edad del Hierro en la Baja Extremadura: problemática y perspectivas en torno al poblamiento". Saguntum, 22. 165-224.

- (1990): "Continuidad y ruptura cultural durante la Segunda Edad del Hierro en Extremadura". La cultura tartésica y Extremadura. Cuadernos Emeritenses, 2. 127-162.

- (1991a): La Ermita de Belén (Zafra, Badajoz). Campaña de 1987.

- (1991b): "Proyecto Hornachuelos: 1986-1990 (Ribera del Fresno, Badajoz)". I Jornadas de Prehistoria y Arqueología en Extremadura. Extremadura Arqueológica, II. 283-300.

- (1994): "Algunas reflexiones sobre el fin de Tartessos en la Cuenca Media del Guadiana: la crisis del cuatrocientos y el desarrollo de la Beturia". Cuadernos de Prebistoria y Arqueología de la Universidad Autónoma de Madrid, 21. 9-34. 
- (1995a): "Territorios y etnias prerromanas en el Guadiana Medio: aproximación a la arqueología de la Beturia Túrdula". Celtas y Túrdulos: la Beturia. Cuadernos Emeritenses, 9. 205-254.

- (1995b): "Extremadura Prerromana". Arqueología en Extremadura: 10 años de descubrimientos. Extremadura Arqueológica, IV. 91-122.

- (1995c): "El problema de la Beturia en el marco del poblamiento protohistórico del Valle Medio del Guadiana". Homenaje a la Dra. Da Milagro Gil-Mascarell Boscà. Extremadura Arqueológica, V. 157-175.

RODRíguez, A. y BerRoCAL, L.: (1988): "Materiales cerámicos de la Segunda Edad del Hierro del Cantamento de la Pepina (Fregenal de la Sierra, Badajoz). Cuadernos de Prehistoria y Arqueología de la Universidad Autónoma de Madrid, 15. 215-252.

RODRiguez, A. E IÑESTA, J. (1984): "Las Dehesillas. Un poblado prerromano en el término municipal de Higuera de Llerena (Badajoz)". Norba, 5. 17-28.

RODRiguez, A. Y JiMÉnEZ, J. (1987-88): "Informe sobre las excavaciones realizadas en el yacimiento de Hornachuelos, Ribera del fresno (Badajoz). 1986-1988". Norba, 8-9. 13-31.

RODRiguez, A. y ORTZZ, P. (1986): "Avance de la primera campaña de excavación en el recinto-torre de Hijovejo (Quintana de La Serena, Badajoz). El sondeo número 2". Norba, 7.

- (1990): "Poblamiento prerromano y recintos ciclópeos de La Serena, Badajoz". Cuadernos de Prehistoria y Arqueología de la Universidad Autónoma de Madrid, 17. 45-65.

- (1998): "La Mata de Campanario (Badajoz): un nuevo ejemplo de Arquitectura de Prestigio en la Cuenca Media del Guadiana". Extremadura Protohistórica: Paleoambiente, Economía y Poblamiento (Coord. Rodríguez Diaz, A.). 201-246.

Romero Carnicero, F. (1984): "La Edad del Hierro en la serranía soriana: los castros". Boletín del Seminario de Arte y Arqueología, L. 27-68.

Roso De LunA, M. (1901): "Poblaciones celto-lusitanas o citanias cacereñas". Boletín de la Real Academia de la Historia, XXXVIII. 422-424.

- (1904a): "Sobre las citanias extremeñas". Boletín de la Real Academia de la Historia, XLV, 507-510.

- (1904b): "Notas arqueológicas". Revista de Extremadura, VIII. 433-439.

- (1908): "Protohistoria extremeña". Boletín de la Real Academia de la Historia, LII. 140151.

Ruiz MATA, D. (1987): "La formación de la cultura turdetana en la Bahía de Cádiz a través del Castillo de Doña Blanca". Iberos. Actas de las IJornadas sobre el mundo ibérico. Jaén, 1985. 299-314.

Ruiz Rodríguez, A. y Nocete Calvo, F. (1981): “Un modelo sincrónico para el análisis de la producción de cerámica ibérica estampillada del Alto Guadalquivir". Cuadernos de Prehistoria de la Universidad de Granada, 6. 355-383.

SALINAS De FRIAS, M. y OTROS (1993): El proceso histórico en la lusitania oriental en época preromana y romana. Cuadernos Emeritenses, 7.

Velázquez, A. y Enríquez, J.J. (Edes.) (1995): Celtas y Túrdulos: la Beturia. Cuadernos Emeritenses, 9. 